\title{
Article
}

\section{Spatiotemporal Variation in Rainfall Erosivity and Correlation with the ENSO on the Tibetan Plateau since 1971}

\author{
Bohao Cui ${ }^{1,2}$, Yili Zhang ${ }^{1,2, *}$, Linshan Liu ${ }^{1}\left(\mathbb{D}\right.$, Zehua $\mathrm{Xu}^{2,3}$, Zhaofeng Wang ${ }^{1,2}$, Changjun Gu ${ }^{1,2}$, Bo Wei ${ }^{1,2}$ \\ and Dianqing Gong ${ }^{1,2}$
}

1 Key Laboratory of Land Surface Pattern and Simulation, Institute of Geographic Sciences and Natural Resources Research, CAS, Beijing 100101, China; cuibh.19b@igsnrr.ac.cn (B.C.); liuls@igsnrr.ac.cn (L.L.); wangzf@igsnrr.ac.cn (Z.W.); gucj.18b@igsnrr.ac.cn (C.G.); weib.20b@igsnrr.ac.cn (B.W.); gongdq.18s@igsnrr.ac.cn (D.G.)

2 College of Resources and Environment, University of Chinese Academy of Sciences, Beijing 100049, China; zhxu_st@rcees.ac.cn

3 State Key Laboratory of Urban and Regional Ecology, Research Center for Eco-Environmental Sciences, Chinese Academy of Sciences, 18 Shuangqing Road, Beijing 100085, China

* Correspondence: zhangyl@igsnrr.ac.cn

Citation: Cui, B.; Zhang, Y.; Liu, L.; Xu, Z.; Wang, Z.; Gu, C.; Wei, B.; Gong, D. Spatiotemporal Variation in Rainfall Erosivity and Correlation with the ENSO on the Tibetan Plateau since 1971. Int. J. Environ. Res. Public Health 2021, 18, 11054. https:// doi.org/10.3390/ijerph182111054

Academic Editor: Paul B. Tchounwou

Received: 17 August 2021

Accepted: 19 October 2021

Published: 21 October 2021

Publisher's Note: MDPI stays neutral with regard to jurisdictional claims in published maps and institutional affiliations.

Copyright: (C) 2021 by the authors Licensee MDPI, Basel, Switzerland. This article is an open access article distributed under the terms and conditions of the Creative Commons Attribution (CC BY) license (https:/ / creativecommons.org/licenses/by/ $4.0 /)$.

\begin{abstract}
Soil erosion is a serious ecological problem in the fragile ecological environment of the Tibetan Plateau (TP). Rainfall erosivity is one of the most important factors controlling soil erosion and is associated with the El Niño southern oscillation (ENSO). However, there is a lack of studies related to the spatial distribution and temporal trends of rainfall erosivity on the TP as a whole. Additionally, the understanding of the general influence of ENSO on rainfall erosivity across the TP remains to be developed. In this study, long-term (1971-2020) daily precipitation data from 91 meteorological stations were selected to calculate rainfall erosivity. The analysis combines co-kriging interpolation, Sen's slope estimator, and the Mann-Kendall trend test to investigate the spatiotemporal patten of rainfall erosivity across the TP. The Oceanic Niño Index (ONI) and multivariate ENSO Index (MEI) were chosen as ENSO phenomenon characterization indices, and the relationship between ENSO and rainfall erosivity was explored by employing a continuous wavelet transform. The results showed that an increasing trend in annual rainfall erosivity was detected on the TP from 1971 to 2020. The seasonal and monthly rainfall erosivity was highly uneven, with the summer erosivity accounting for $60.36 \%$. The heterogeneous spatial distribution of rainfall erosivity was observed with an increasing trend from southeast to northwest. At the regional level, rainfall erosivity in the southeastern TP was mainly featured by a slow increase, while in the northwest was more destabilizing and mostly showed no significant trend. The rainfall erosivity on the whole TP was relatively high during non-ENSO periods and relatively low during El Niño/La Niña periods. It is worth noting that rainfall erosivity in the northwest TP appears to be more serious during the La Niña event. Furthermore, there were obvious resonance cycles between the rainfall erosivity and ENSO in different regions of the plateau, but the cycles had pronounced discrepancies in the occurrence time, direction of action and intensity. These findings contribute to providing references for soil erosion control on the TP and the formulation of future soil conservation strategies.
\end{abstract}

Keywords: rainfall erosivity; soil erosion; spatiotemporal variation; ENSO; Tibetan Plateau

\section{Introduction}

Soil erosion has already emerged as one of the most serious ecological and environmental problems globally, which not only threatens terrestrial ecosystems, but also severely restricts the security of human existence and the sustainable development of economy and society [1,2]. Soil erosion not only contributes to land degradation, but even interferes with the ability of the soil carbon cycle to mitigate the greenhouse effect $[3,4]$. Soil erosion by water is considered to be one of the most detrimental types of soil erosion, causing a 
loss of soil nutrients, which reduces crop yields, pollutes water quality, contributes to the sedimentation of rivers, and raises flooding [5-9]. Therefore, the accurate prediction of water erosion is of great significance for the comprehensive management of soil erosion and effective soil protection.

The causes of water erosion are related to a series of natural factors involving rainfall, soil, topography, vegetation, and other human factors such as land use and crop cultivation management $[10,11]$. In particular, rainfall is the principal climatic factor responsible for water erosion, which influences water erosion through the duration, amount, and intensity of rainfall events [12]. The principal predictive tools for water erosion are the Universal Soil Loss Equation (USLE) and the Revised Universal Soil Loss Equation (RUSLE), which have been applied worldwide, and rainfall erosivity (R-factor), one of the key input parameters in the model, is the potential capacity of rainfall to induce water erosion [12,13]. The $\mathrm{R}$-factor is defined as the product of the rainfall energy and the maximum rainfall intensity in a $30 \mathrm{~min}$ period (EI30), and the calculation requires the use of consecutive rainfall data series with a temporal resolution of at least $15 \mathrm{~min}$, which is however, hardly available in many countries and regions. Even if an adequate rain gauge data can be accessed, the complicated calculation process is time-consuming and laborious, which dramatically restricts model promotion and implementation [14].

In this context, as alternative algorithms based on the relationship between R-factor and available rainfall data were developed, including the calculation of rainfall erosivity based on annual $[15,16]$, monthly $[17,18]$, and daily $[19,20]$ rainfall data from meteorological stations or satellite radar [21,22]. Among these, daily rainfall data are widely used due to their relative accessibility, which provides more characteristic information of rainfall and facilitates the precision and reliability of R-factor estimation [23]. In the daily rainfall data model, the rainfall erosivity algorithm was divided into linear exponential, logarithmic, and power functions to fit the relationship between rainfall and rainfall erosivity, and the models are mostly combined experimental and empirical based [24-26]. In general, these models perform an important role in the quantitative evaluation of rainfall erosivity, and provide scientific reference for the forming mechanism of water erosion, evolutionary process and even the mechanics of climate change.

It has become an indisputable fact that the global climate is changing remarkably, with extreme weather events growing stronger, more frequent, and lasting longer [27]. El Niño southern oscillation (ENSO) is the most intense sea-air interaction event affecting the global climate, and although it usually occurs in the eastern equatorial Pacific region, it can be responsible for rainfall anomalies spreading globally [28]. The ENSO cycle has a pronounced periodic character as a result of the interaction between the ocean and the atmosphere, with El Niño (warm phase) and La Niña (cold phase) as the two extreme phases of the ENSO cycle. Considerable work has been conducted on the relationship between ENSO and precipitation events, anomalous temperature, wet and dry variability, and atmospheric circulation [29-32]. The studies also pointed out that El Niño and La Niña showed diverse rainfall patterns, for example, compared with the La Niña period, northern China is more arid during El Niño in the northern hemisphere, while rainfall in the southeast of China appears to increase substantially, while the contrary phenomenon is present in the southern hemisphere [33,34]. Although these studies have enhanced our comprehension of atmospheric tele-correlation model (ENSO) effects on rainfall, currently the effect of ENSO on rainfall erosivity is still only shown in a few studies [35-39]. A significant dependence between rainfall erosivity and the ENSO indices has been observed in eastern China [35,37], northeastern Spain [40], and the southwestern United States [41], while studies on how ENSO affects rainfall erosivity on the TP are still unknown.

The Tibetan Plateau (TP) is the largest and highest geographical unit in the world, with an average altitude of over $4000 \mathrm{~m}$, and is called the Earth's "third pole". It is of extreme importance to regional economic development and ecological security, as well as global climate, water resources, and ecosystem functioning [42]. Since the 21st century, however, drastic environmental changes have been remarkably observed on the TP [43]. These 
changes have become key drivers of increased soil erosion risk. Studies have demonstrated that grassland ecosystems on the TP are suffering from severe degradation due to the combined effects of climate change and human activities. This in turn has triggered a decline in biomass, biodiversity, and landscape complexity, fragmentation or complete loss of services such as soil and water conservation, and an increase in rainfall erosivity and sandstorms [44-47]. Permafrost degradation can reduce the stability of soil aggregates and the water content in the surface soil is abnormally high during the thawing stage, thus shortening the time of runoff generation and exacerbating erosion caused by rainfall [48,49]. The glaciers' retreat and the rise of the snow line in cold areas at high altitudes have changed the surface albedo and atmospheric heat circulation and thus have affected the local rainfall intensity, and the form of erosion caused by glacial meltwater and snowmelt runoff generated is one of the main reasons for increased erosion [50,51]. Additionally, according to observations and climatological models, the TP has suffered a faster rate of warming since the 1960s, which is three times the global average [52]. Notable changes in the plateau climate system, such as short periods of intense rainfall triggered by extreme precipitation events, may have led to an increasing trend in the rainfall erosivity on the TP [51]. Some studies have analyzed the variation in rainfall erosivity in the catchment and local scales of the TP, indicating an increasing trend of rainfall erosivity [53-55]. These studies provided useful information on the variation in rainfall erosivity, but a further analysis is necessary for the TP as a whole.

Soil erosion is serious on the TP, with $70 \%$ of the area suffering from varying degrees of soil erosion [56]. In both sides of the Yarlung Tsangpo River and the South Qiangtang area, gully erosion is widely distributed, while in the interior of the plateau scale erosion becomes the main type of erosion in grasslands [57]. Soil erosion on the TP has caused irreparable soil degradation and land area reduction, and is leading to the sedimentation of downstream rivers, landslides, mudslides and other disasters, posing a threat to transportation, agriculture, and animal husbandry. Moreover, soil conservation is particularly important in the TP due to its harsh physical environment, widespread permafrost and fragile alpine ecosystems making it the most sensitive and fragile region [58]. Once erosion happens, its rehabilitation process is prolonged and difficult.

Detection of long-term trends in rainfall erosivity can provide information regarding the potential impact of rainfall changes on soil erosion. It is particularly useful for the TP region, which is more sensitive to water erosion and climate change because of the fragile biophysical conditions [59]. However, these unique geographical features and complicated terrain have restricted soil erosion studies due to the scarce observational data on precipitation and soil erosion. Previous studies have focused on local watersheds or small areas of the TP, while the spatial and temporal characteristics of how rainfall erosivity vary over the entire TP have not been adequately studied [60,61]. Moreover, periodic factors lead to 'poverty years' and 'abundant years' of precipitation in the highlands in different years. The interannual variation in precipitation erosivity on the TP may be the result of ENSO action, but the general effect of ENSO on rainfall erosivity in the TP is not clear at present, and it is necessary to expand the related understanding.

In view of this, the TP as a whole was chosen as the study area, and daily rainfall data from 91 meteorological stations were selected to calculate the rainfall erosivity and to explore its relationship with ENSO. The objectives of the study are as follows: (1) to characterize the temporal trends of rainfall erosivity during 1971-2020 across the entire TP; (2) to present the spatial distribution of rainfall erosivity on the TP; (3) and to investigate the impacts of ENSO on rainfall erosivity in different regions of the TP.

\section{Materials and Methods}

This study was based on a single case study of the TP. In this section, the basic information about the study area, the required data handling process and the methods related to rainfall erosivity were described in detail. 


\subsection{Study Area}

The Tibetan Plateau is located in the southwestern part of China, with an area of $2.74 \times 10^{6} \mathrm{~km}^{2}$ and an average altitude of over $4000 \mathrm{~m}$. It is known as the "roof of the world" [62]. It is included in the Tibet Autonomous Region and Qinghai Province, and the southern part of the Xinjiang Uygur Autonomous Region, the western part of Gansu Province, the western part of Sichuan Province and the northern part of Yunnan Province. The main mountain ranges are the Kunlun Mountains, Qilian Mountains, Karakorum Mountains, Himalayas, and Hengduan Mountains. The climate ranges from a humid monsoon climate in the southeast to an alpine arid plateau climate in the northwest, controlled by the Pacific monsoon, Indian monsoon, and prevailing westerly winds, and is influenced by the mountain terrain [63]. Diverse climate types form subtropical rainforests, shrubs, alpine meadows, alpine grasslands, and alpine desert vegetation types are present. TP precipitation exhibits a distinct gradient, gradually decreasing from more than $1000 \mathrm{~mm}$ in the southeast to less than $50 \mathrm{~mm}$ in the northwest [64]. The region has experienced soil erosion, desertification and landslide hazard [51,65]. Referring to [66], the criteria for the physical geographic zoning of the TP divided the plateau into Region I (arid zone) and Region II (humid zone) (Figure 1).

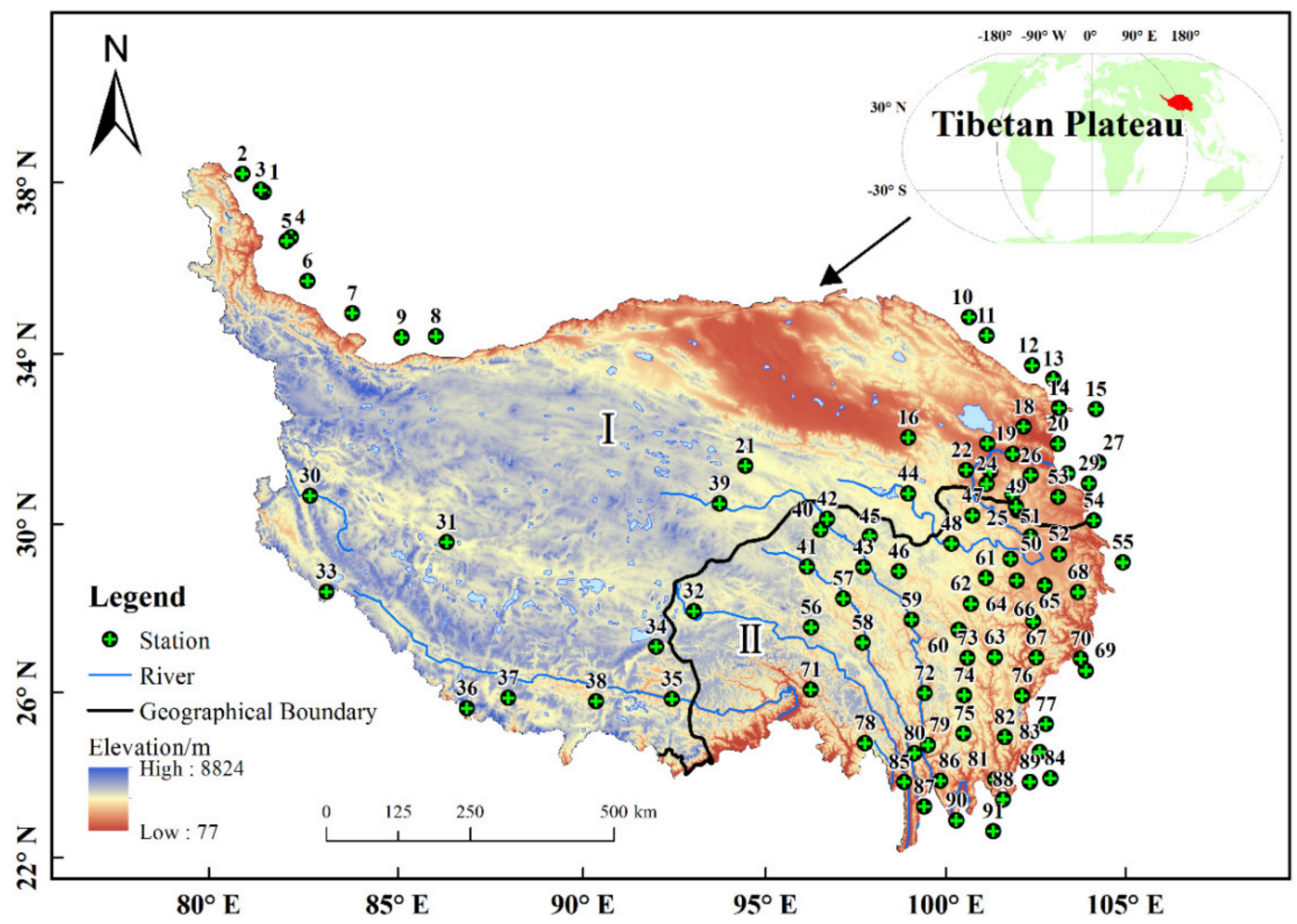

Figure 1. Study area of Tibetan Plateau (TP) and the distribution of meteorological stations.

\subsection{Database}

\subsubsection{Daily Rainfall Data}

The observed daily precipitation data used in this study was obtained from the Climatic Data Center, National Meteorological Information Center of the China Meteorological Administration (CMA) (http:/ / data.cma.cn (accessed on 10 October 2021)). The data included a total of 91 meteorological stations (Figure 1), with complete data series, covering the time period 1971 to 2020 (Table S1). Moreover, considering the continuity of spatial interpolation and the stations spreading over the entire TP as much as possible, 27 meteorological stations around the study area were selected with the criterion that the shortest linear distance from a meteorological station to the TP boundary is not greater than $100 \mathrm{~km}$. The observation records of all surrounding stations were recorded at the same time as the 
study period. In order to ensure data reliability and continuity, each meteorological data record was evaluated by the National Meteorological Center [67].

\subsubsection{ENSO Indices}

ENSO is a phenomenon of irregular periodic changes in sea surface temperature and wind occurring in the equatorial eastern Pacific Ocean, one of the strongest natural signals of interannual climate change worldwide. The typical characteristics of ENSO events are commonly known to be anomalous SSTs $\left( \pm 0.5^{\circ} \mathrm{C}\right)$ in the eastern Pacific Ocean for more than 5 months, where warm episodes are El Niño events and cold episodes are La Niña events $[68,69]$. The multivariate ENSO Index (MEI) was obtained as the first non-rotating principal component $(\mathrm{PC})$ of the six variables (sea-level pressure, zonal and meridional components of the surface wind, sea surface temperature, surface air temperature, total cloudiness fraction of the sky) over the tropical Pacific [70,71]. it is considered as a better index for detecting the ENSO phenomena with respect to other indices because it takes into account more information and fewer data failures [37]. Therefore, in this study, the occurrence and duration of the El Niño event and La Niña event were determined based on the Oceanic Niño Index (ONI), and MEI was selected as the ENSO proxy to probe the relationship between rainfall erosivity and ENSO during the time period of 1971-2020. These indexes are obtained from the National Oceanic and Atmospheric Administration (NOAA). Specifically, ONI was acquired from NOAA Climate Prediction Center [72], and MEI was acquired from NOAA Earth System Research Laboratory.

\subsection{Methods}

\subsubsection{Technical Route}

The study was divided into four steps (Figure 2):

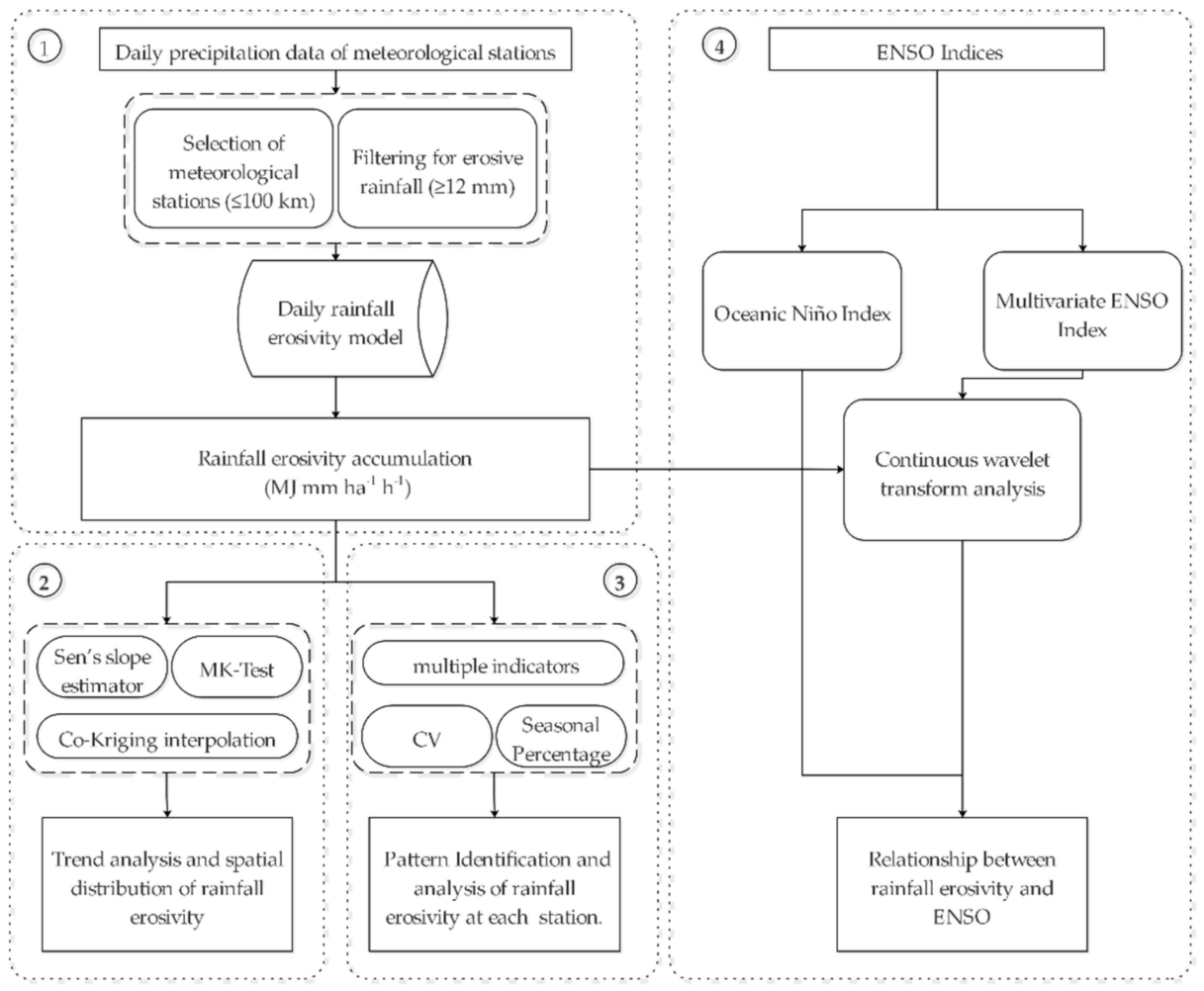

Figure 2. Technical route. Note: MK-test refers to Mann-Kendall test, CV refers to the coefficient of variation. 
Step 1: Estimation of rainfall erosivity at different time scales. Based on the daily rainfall data of 91 stations, the annual, seasonal, and monthly average rainfall erosivity of TP from 1971 to 2020 were calculated using the daily rainfall erosivity model.

Step 2: Trend analysis and spatial distribution of rainfall erosivity in TP. Firstly, the temporal changes trend of rainfall erosivity was evaluated by using Sen's slope estimation and the MK trend test, and then the co-kriging method was used for the spatial mapping of rainfall erosivity for the period of 1971-2020.

Step 3: Pattern identification and analysis of rainfall erosivity change at each meteorological station. Firstly, the change trend of rainfall erosivity at each station was classified by integrating multiple indicators. Then, the coefficient of variation $(\mathrm{CV})$ and the seasonal spatial distribution of rainfall erosivity of each site was analyzed.

Step 4: Relationship between rainfall erosivity and ENSO. Based on ONI, the variation in monthly mean rainfall erosivity during El Niño and La Niña events from 1971 to 2020 was analyzed; based on the MEI index, a continuous wavelet transform analysis method was used to examine the influence of ENSO on rainfall erosivity, and to clarify the response of the resonance period in different regions of the TP.

\subsubsection{Calculation of Rainfall Erosivity}

The half-monthly rainfall erosivity was estimated for each of the 91 meteorological stations from 1971 to 2020 using the daily rainfall erosivity model. The agent model was originally built from Richardson's equation [73], and later improved by Zhang [20]. Previous studies have demonstrated that this method is reliable and has been widely used on the national and regional scales in China [36,74-76]. This method is based on daily rainfall data to obtain monthly, seasonal, and annual rainfall erosivity. The calculation procedures are as follows:

$$
\begin{gathered}
R_{i}=\alpha \sum_{j=1}^{k}\left(P_{j}\right)^{\beta} \\
\alpha=21.586 \beta^{-7.1981} \\
\beta=0.8363+\frac{18.144}{P_{(d 12)}}+\frac{24.455}{P_{(y 12)}}
\end{gathered}
$$

where $R_{\mathrm{i}}$ is the rainfall erosivity in the $i$-th half-month period (MJ mm ha-1 $\mathrm{h}^{-1}$ ), $k$ is the number of days in the half-month period, and $P_{j}$ is the daily erosive rainfall amount $(\mathrm{mm})$ on the $j$-th day during the half-month period. The half-month interval method is as follows: with the fifteenth day of each month as the dividing point, the whole year is divided into 24 half months. The half-month period as a basic statistical unit is used to calculate the corresponding half-month rainfall erosivity.

According to the national rainfall and runoff analysis, $\geq 12 \mathrm{~mm}$ is defined as erosive rainfall [77]. Therefore, the daily rainfall $\geq 12 \mathrm{~mm}$ is applied to Formula (1), otherwise, it is regarded as value of 0 in the calculations.

The terms $\alpha$ and $\beta$ are two parameters to be determined in the model. $P_{(d 12)}$ is the average daily erosive rainfall amount $(\mathrm{mm})$ and $P_{(y 12)}$ is the average annual erosive rainfall amount (mm). In this study, Formulas (1)-(3) are used to calculate the half-month rainfall erosivity of each meteorological station. The annual and seasonal rainfall erosivity of is the cumulative value of rainfall erosivity in every half-month period.

\subsubsection{Sen's Slope Estimator and Mann-Kendall Test}

In this study, the trends magnitude of annual rainfall erosivity was estimated with the non-parametric Sen's method. The trends and significance of annual and seasonal (monthly) rainfall erosivity were detected with the non-parametric Mann-Kendall test.

Sen's slope estimation is a non-parametric method of slope calculation, which is commonly used in the trend analysis due to its high robustness and computational efficiency [78]. The determination for the slope of annual rainfall erosivity is as follows: first, 
the values of $Q_{i}$ calculated by the Formula (4) are ranked in order of magnitude, and then determines the overall estimator (SLOPE $E_{m e d}$ ) as the median of these $Q_{i}$ by Formula (5).

The slope in the $N$ pairs of samples is calculated as follows:

$$
Q_{i}=\frac{x_{j}-x_{k}}{j-k}(i=1, \ldots, N)
$$

where $x_{j}$ and $x_{k}$ are values of the rainfall erosivity corresponding to periods $j$ and $k$, respectively $(j>k)$. SLOPE $E_{\text {med }}$ is calculated according to the following formula:

$$
S L O P E_{\text {med }}= \begin{cases}Q_{\left[\frac{N+1}{2}\right]}<0 & \text { if } N \text { is odd } \\ \frac{Q_{\left[\frac{N+1}{2}\right]}+Q_{\left[\frac{N+1}{2}\right]}}{2} & \text { if } N \text { is even }\end{cases}
$$

where $S L O P E_{\text {med }}>0$ indicates an upward trend, and vice versa. Its value indicates the magnitude of the trend change.

The non-parametric Mann-Kendall test is a widely used technique for to assess the significance of trends in long time series [79,80]. It is distribution free and not affected by missing values and outliers, and is highly recommended by the World Meteorological Organization [81]. This method is primarily based on two parameters, $S$ and $Z$, to determine whether a time series has a significant trend. The intermediate variable $S$ is computed as:

$$
S=\sum_{k=1}^{n-1} \sum_{j=k+1}^{n} \operatorname{sgn}\left(x_{j}-x_{k}\right)
$$

where $n$ is the length of the time series, $x_{j}$ and $x_{k}$ are values of the rainfall erosivity corresponding to periods $j$ and $k$, respectively $(j>k)$. $S$ is the summation of $\operatorname{sgn}\left(x_{j}-x_{k}\right)$, which takes the value of $-1,0$, or 1 when $\left(x_{j}-x_{k}\right)$ is less than, equal to, or greater than 0 , respectively. The variance of $S$ can be acquired as follows:

$$
\operatorname{var}(S)=\frac{n(n-1)(2 n+5)}{18}
$$

Then the normalized statistical value $\mathrm{Z}$ is denoted as follows:

$$
Z= \begin{cases}\frac{S-1}{\sqrt{\operatorname{var}(S)}} & \text { if } S>0 \\ 0 & \text { if } S=0 \\ \frac{S+1}{\sqrt{\operatorname{var}(S)}} & \text { if } S<0\end{cases}
$$

where a positive (negative) value of $Z$ indicates an upward (downward) trend. In bilateral trend detection, a time series with a significant trend is indicated if $|Z| \geq Z_{1-\alpha / 2}$ at a certain significance level $\alpha$, where $Z_{1-\alpha / 2}$ is obtained from the standard normal cumulative distribution tables. The trend is statistically significant at the $0.1,0.05$, and 0.01 significance level when $|Z|>1.645,1.96$ and 2.576, respectively. Besides, the Mann-Kendall test can also be used to detect the abrupt points. The abrupt points and the approximate time of occurrence can be located according to the intersection of the progressive and retrograde sequences within the sequence. More details of the abrupt points calculation on the Mann-Kendall Test are available from the network resources.

\subsubsection{Spatial and Statistical Analysis}

The mean annual rainfall erosivity at each of the 91 stations was calculated by a long-term (1971-2020) average value of annual rainfall erosivity. Based on these station's values, the co-kriging interpolation method was used to interpolate the spatial distribution of the average annual erosivity of the TP, using the geostatistical analysis tool ArcGIS 10.4.

Different from the inverse distance weighting (IDW) method which only considered one assumption: nearby points should be closer to the value of the interpolation position 
than distant points, the co-kriging interpolation method allowed the addition of covariates to improve the accuracy of estimation or prediction $[74,82]$. Considering the complex terrain of the TP, the elevation factor was defined as a co-variable in the co-kriging interpolation method [36]. The elevation data of each meteorological station was provided by the China Meteorological Administration (CMA). Based on the values of rainfall erosivity for 91 meteorological stations on the TP, the co-kriging interpolation method was performed and generated the spatial distribution map of rainfall erosivity for the period of 1971-2020.

In this study, the rainfall erosivity anomalies of the TP is expressed as the difference between the annual erosivity value of the observation year and the 50-year average value. The 5-year moving average anomaly can smooth fluctuations and reduce potential errors, and was used to analyze the temporal changes of the rainfall erosivity across the TP. The seasonal (monthly) average rainfall erosivity of the TP was calculated by averaging the seasonal (monthly) erosivity of 91 meteorological stations during the same time span, from 1971 to 2020. The annual variation from the meteorological site is represented by the coefficient of variation $(\mathrm{CV})$, which is expressed as a percentage of the standard deviation of the annual erosivity to the average of the observation year. The map of seasonal spatial distribution of rainfall erosivity is expressed as a percentage of the seasonal rainfall erosivity in the annual total erosivity at each weather station.

\subsubsection{Identification of Rainfall Erosivity Trend Patterns}

With reference to the time series trend identification method of Ray [83], rainfall erosivity change patterns were identified for each meteorological station from 1971 to 2020 . Multiple indicators were integrated: the $Z$ values calculated by Mann-Kendall, SLOPE\% and $R_{S T}$.

The SLOPE\% value represents as a percentage of SLOPE for the average rainfall erosivity for each meteorological station during 1971-2020. The calculation formula is as follows:

$$
S L O P E \%=\frac{S L O P E}{\left(\sum_{i=1}^{n} x_{i}\right) / n} \times 100
$$

where SLOPE is the Sen's slope value of rainfall erosivity changes, $x_{i}$ is the value of the rainfall erosivity corresponding to period $i$, and $n$ is the length of the time series. The $R_{S T}$ is defined as the ratio of the average rainfall erosivity for the last 3 years to the maximum 3 year moving average. This is used to identify whether the increasing trend of annual rainfall erosivity is interrupted, shifting to a decline at later stages. The equation is expressed below:

$$
R_{S T}=\frac{\operatorname{ave}\left(x_{n-2}, x_{n-1}, x_{n}\right)}{\max \left(A \operatorname{VE}\left(x_{1}, x_{2}, x_{3}\right), \operatorname{AVE}\left(x_{2}, x_{3}, x_{4}\right), \ldots A V E\left(x_{n-2}, x_{n-1}, x_{n}\right)\right)}
$$

where $x_{i}$ is the value of the rainfall erosivity corresponding to period $i$, and $n$ is the length of the time series.

The trend of rainfall erosivity was classified by the above-mentioned three indicators into four patterns of decreasing, stagnant, increasing-stagnant and increasing (Table 1), abbreviated as DE, ST, IN-ST and IN, respectively. The $Z$ value indicates whether there is a significant trend of rainfall erosivity $(|Z|>1.96$ at the 0.05 significance level), a nonsignificant change trend $(0.675<|Z| \leq 1.96$ at the $0.05-0.5$ significance level), and no change trend $(|Z| \leq 0.675$ at the below 0.5 significance level); SLOPE\% indicates whether the magnitude of the rainfall erosivity trend change is significant. References $[84,85]$ used $0.25 \%$ as a criterion, i.e., a change greater than $0.25 \%$ is assumed to be significant. $R_{S T}$ is used to determine whether the annual rainfall erosivity growth trend is interrupted, or turns down and mitigates at a later stage. 
Table 1. Definition and indicators of rainfall erosivity trend patten.

\begin{tabular}{ccc}
\hline Trend Patten & Definition & Identification Indicators \\
\hline \multirow{2}{*}{ DE } & $\begin{array}{c}\text { Rainfall erosivity decreased significantly } \\
\text { during the study period }\end{array}$ & $\begin{array}{c}Z<-1.96, \text { or } 1.96 \leq Z<-0.675 \text { and } \\
S L O P E \%<-0.25 \%\end{array}$ \\
\hline \multirow{2}{*}{ ST } & $\begin{array}{c}\text { Rainfall erosivity showed no significant } \\
\text { change during the study period }\end{array}$ & $\begin{array}{c}|Z|<0.675, \text { or } 0.675 \leq|Z|<1.96 \text { and } \\
|S L O P E \%|<0.25 \%\end{array}$ \\
\hline \multirow{2}{*}{ IN-ST } & $\begin{array}{c}\text { Rainfall erosivity showed an increasing } \\
\text { trend in the early stage, but showed a } \\
\text { stable trend in the later stage }\end{array}$ & $\begin{array}{c}0.675 \leq Z<1.96 \text { and } S L O P E \%>0.25 \% \\
\text { and } R_{S T}<1, \text { or } Z \geq 1.96 \text { and } R_{S T}<1\end{array}$ \\
\hline \multirow{2}{*}{ IN } & $\begin{array}{c}\text { Rainfall erosivity showed a gradual } \\
\text { increase trend during the study period }\end{array}$ & $\begin{array}{c}0.675<Z<1.96 \text { and } S L O P E \%>0.25 \% \text { and } \\
R_{S T}=1, \text { or } Z \geq 1.96 \text { and } R_{S T}=1\end{array}$ \\
\hline
\end{tabular}

Note: The $Z$ value indicates the MK trend detection value, the $S L O P E \%$ is the trend change rate percentage, and the $R_{S T}$ refers to the ratio of the rainfall erosivity in the past 3 years to the maximum 3-year moving average. DE: decreasing, ST: stagnating, IN-ST: increasing-stagnating, IN: increasing.

\subsubsection{Continuous Wavelet Transform Analysis}

The continuous wavelet transform (CWT) is a method to decompose a time series into a two-dimensional phase plane of the time-frequency simultaneously. It is commonly applied to the analysis of various hydrological and meteorological processes with high variability to detect non-stationary trends, periodicities, and durations as it better characterizes oscillatory behaviors of signals than discrete wavelet transforms [86-88]. Specifically, two CWTs, cross wavelet transform (XWT), and wavelet transform coherence (WTC), were constructed to investigate whether there is any periodicities or correlations between rainfall erosivity and ENSO. The XWT reveals regions of high common power in the timefrequency spectrum, and calculates the phase relationships between signals. The WTC identifies two time series variation correlations in both time and frequency space, even in the absence of high-power regions. In this study, the wavelet power spectrum of CWT was employed to analyze the relationship and the possible periodicity between rainfall erosivity in different regions and changing patterns of MEI. XWT revealed high common power regions and phase relationships between the two variables, and WTC was used to determine the correlation position of the two variables at local scales. The CWT toolbox package for MATLAB was used to perform all wavelet analyses. For further details about CWT, refer to [89].

\section{Results}

In the following section, the results are represented according to the technical approach mentioned in Section 2. This section analyzed the variability characteristics of rainfall erosivity at different time scales and the spatial distribution pattern of rainfall erosivity at each station, while identifying the relationship between rainfall erosivity and ENSO on the TP.

\subsection{Variation Characteristics of Annual Rainfall Erosivity}

Sen's slope estimation analysis showed an increasing trend of rainfall erosivity on the Tibetan Plateau from 1971 to 2020, with a Sen's slope value of 2.69 for annual rainfall erosivity (Figure 3). The average annual erosivity range from 713.50 to $1495.41 \mathrm{MJ} \cdot \mathrm{mm} \cdot \mathrm{ha}^{-1} \cdot \mathrm{h}^{-1}$, with a multi-year average erosivity of $1071.42 \mathrm{MJ} \cdot \mathrm{mm} \cdot \mathrm{ha}^{-1} \cdot \mathrm{h}^{-1}$. An anomaly analysis indicated obvious inter-annual fluctuation in rainfall erosivity. The magnitude of rainfall erosivity undulation was relatively small until 1996 and increased significantly after 1996, with longer fluctuation periods. For the entire study period, the annual rainfall erosivity was above the mean for the same duration as the periods below the mean, with the highest value of $1495.41 \mathrm{MJ} \cdot \mathrm{mm} \cdot \mathrm{ha}^{-1} \cdot \mathrm{h}^{-1}$ in 2020 ; the lowest value of $713.50 \mathrm{MJ} \cdot \mathrm{mm} \cdot \mathrm{ha}^{-1} \cdot \mathrm{h}^{-1}$ in 2009; the extreme value ratio was 2.1 (Figure S1). Meanwhile, the Mann-Kendall trend analysis had a $Z$ value of 1.67 , indicating that this trend passed the significance test at the $90 \%$ confidence level, with the mutation point occurring in approximately 2017 (Figure S2). 


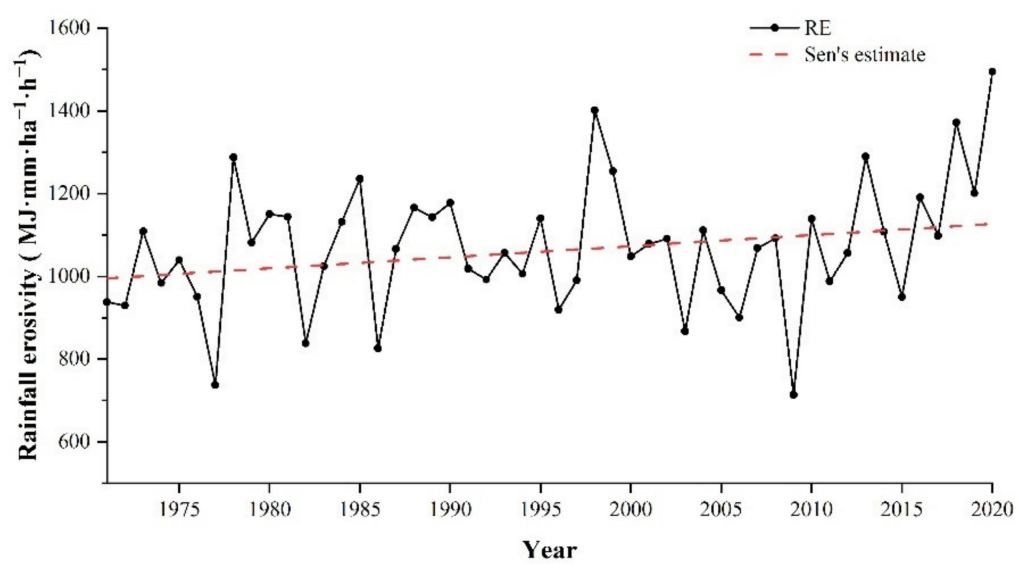

Figure 3. Annual variation in rainfall erosivity on the TP from 1971 to 2020, the red dotted line represents Sen's estimate.

\subsection{Changes in Seasonal and Monthly Rainfall Erosivity}

The seasonal mean rainfall erosivity showed significant discrepancies at 91 meteorological stations on the TP. The rainfall erosivity in order was summer $>$ autumn $>$ spring $>$ winter, with a range of $89.33-662.58 \mathrm{MJ} \cdot \mathrm{mm} \cdot \mathrm{ha}^{-1} \cdot \mathrm{h}^{-1}$. In particular, the average rainfall erosivity in summer was the highest, accounting for $60.36 \%$, while winter was the lowest, accounting for only $8.14 \%$ of the total annual erosivity (Figure 4 ). This phenomenon was mainly influenced by the heterogeneity of the seasonal distribution of precipitation. With the transport of water vapor from the North Indian and Western Pacific monsoons, the summer monsoon brought $58.5 \%$ of the year's rainfall, while late spring and early autumn accounted for $90 \%$ of the year's rainfall [90]. As shown in Figure S3, the summer rainfall erosivity showed a non-significant increasing trend, with the MK statistical value of 1.54 . In contrast, there was a decreasing trend in spring, autumn, and winter rainfall erosion; the spring and autumn MK statistic passed the significance test $(p=0.05)$, which were -2.19 and -2.09 , respectively.

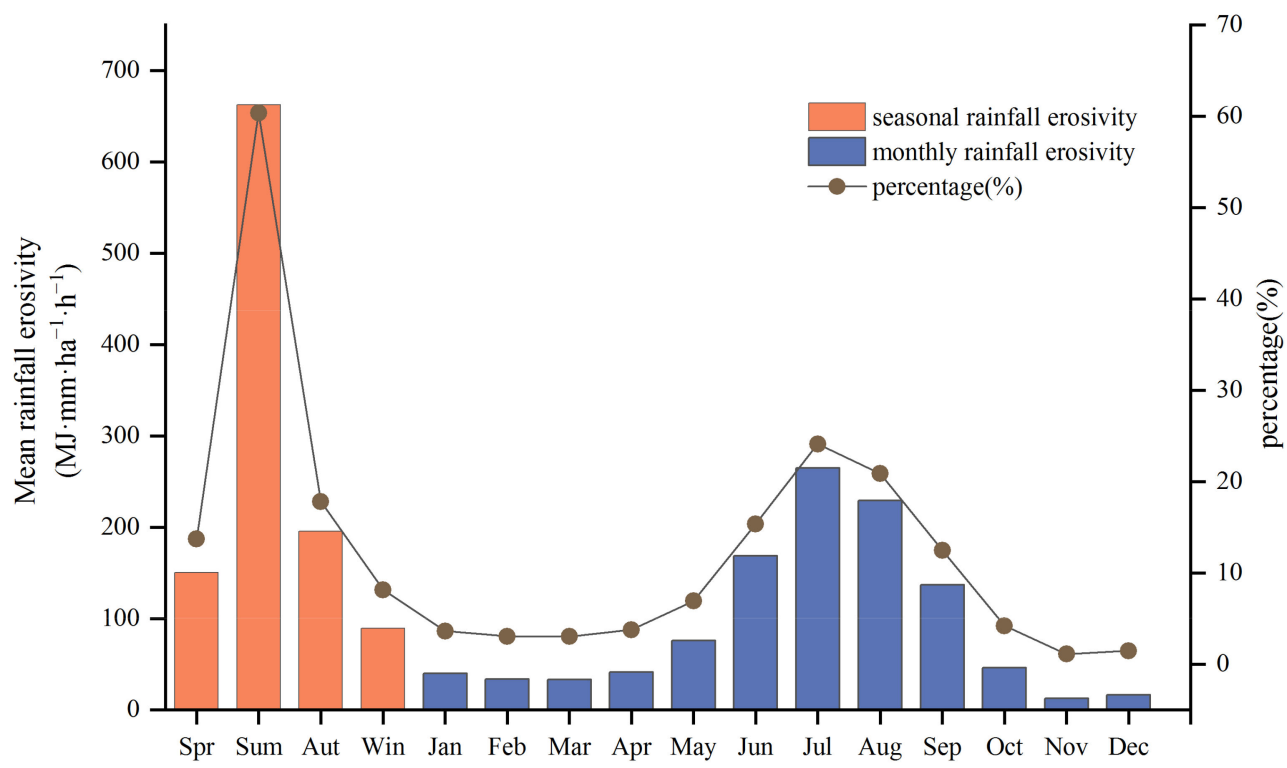

Figure 4. Statistics of seasonal and monthly average rainfall erosivity and its percentage.

Although the monthly average rainfall erosivity was highly variable, there was a clear temporal consistency with the seasonal rainfall erosivity. June, July, and August, corresponding to summer, were the three months with the highest percentage of rainfall 
erosivity for the year. The monthly rainfall erosivity was $168.73 \mathrm{MJ} \cdot \mathrm{mm} \cdot \mathrm{ha}^{-1} \cdot \mathrm{h}^{-1}, 264.75$, and 229.10 MJ $\cdot \mathrm{mm} \cdot \mathrm{ha}^{-1} \cdot \mathrm{h}^{-1}$, respectively. Rainfall erosivity was highest on the Tibetan Plateau in July, the proportion of erosivity reached $24.19 \%$ for the year. November was the lowest with $1.12 \%$, but a higher variability was found in this period, with a high extreme ratio of 18.71 (Figure 4). The trends in the monthly average rainfall erosivity from 1971 to 2020 were further examined, showing an increasing trend in eight months and a decreasing trend in four months. Specifically, the greatest increasing trend in mean rainfall erosivity was in August, but the increasing trend was insignificant in all months. Three months showed a significant decreasing trend, including March and April at 90\% and 95\% confidence levels, respectively, and the most significant decreasing trend was in November, which passed 99\% confidence level (Figure S3).

\subsection{Spatial Patten of Rainfall Erosivity in the Tibetan Plateau}

In order to reduce the boundary effect on the annual rainfall erosivity spatial pattern, 91 meteorological stations were selected for the interpolation better to reveal the spatial variation in rainfall erosivity. In general, the rainfall erosivity on the TP from 1971 to 2020 had obvious spatial differences, roughly exhibiting a spatial pattern of decreasing distribution from southeast to northwest (Figure 5). The high value zone of rainfall erosivity was approximately in the southeastern part of the TP, mainly distributed in the lower altitude regions such as the Hengduan Mountains and the Yarlung Tsangpo Valley. There were three stations with an average annual rainfall erosivity greater than $6000 \mathrm{MJ} \cdot \mathrm{mm} \cdot \mathrm{ha}^{-1} \cdot \mathrm{h}^{-1}$, of which the highest value occurs at Dujiangyan station in Sichuan Province, with an average annual rainfall erosivity of $6605.21 \mathrm{MJ} \cdot \mathrm{mm} \cdot \mathrm{ha}^{-1} \cdot \mathrm{h}^{-1}$. The other two stations are Gongshan station and Huaping station in Yunnan Province, with an average annual rainfall erosivity of $6152.44 \mathrm{MJ} \cdot \mathrm{mm} \cdot \mathrm{ha}^{-1} \cdot \mathrm{h}^{-1}$ and $6193.75 \mathrm{MJ} \cdot \mathrm{mm} \cdot \mathrm{ha}^{-1} \cdot \mathrm{h}^{-1}$, respectively. The zones with low average annual rainfall erosivity were mainly found in the northern and western parts of the TP, including concentrations in the Qiangtang Plateau and the Qaidam Basin. For example, the lowest value was at Shiquanhe station in the Tibet Autonomous Region, where the annual rainfall erosivity was only $103.46 \mathrm{MJ} \cdot \mathrm{mm} \cdot \mathrm{ha}^{-1} \cdot \mathrm{h}^{-1}$. In summary, the average annual rainfall erosivity was less than $500 \mathrm{MJ} \cdot \mathrm{mm} \cdot \mathrm{ha}^{-1} \cdot \mathrm{h}^{-1}$ which accounted for $48.35 \%$ of all stations, $500-1000 \mathrm{MJ} \cdot \mathrm{mm} \cdot \mathrm{ha}^{-1} \cdot \mathrm{h}^{-1}$ for $24.16 \%$ and that of more than $1000 \mathrm{MJ} \cdot \mathrm{mm} \cdot \mathrm{ha}^{-1} \cdot \mathrm{h}^{-1}$ accounted for $27.47 \%$.

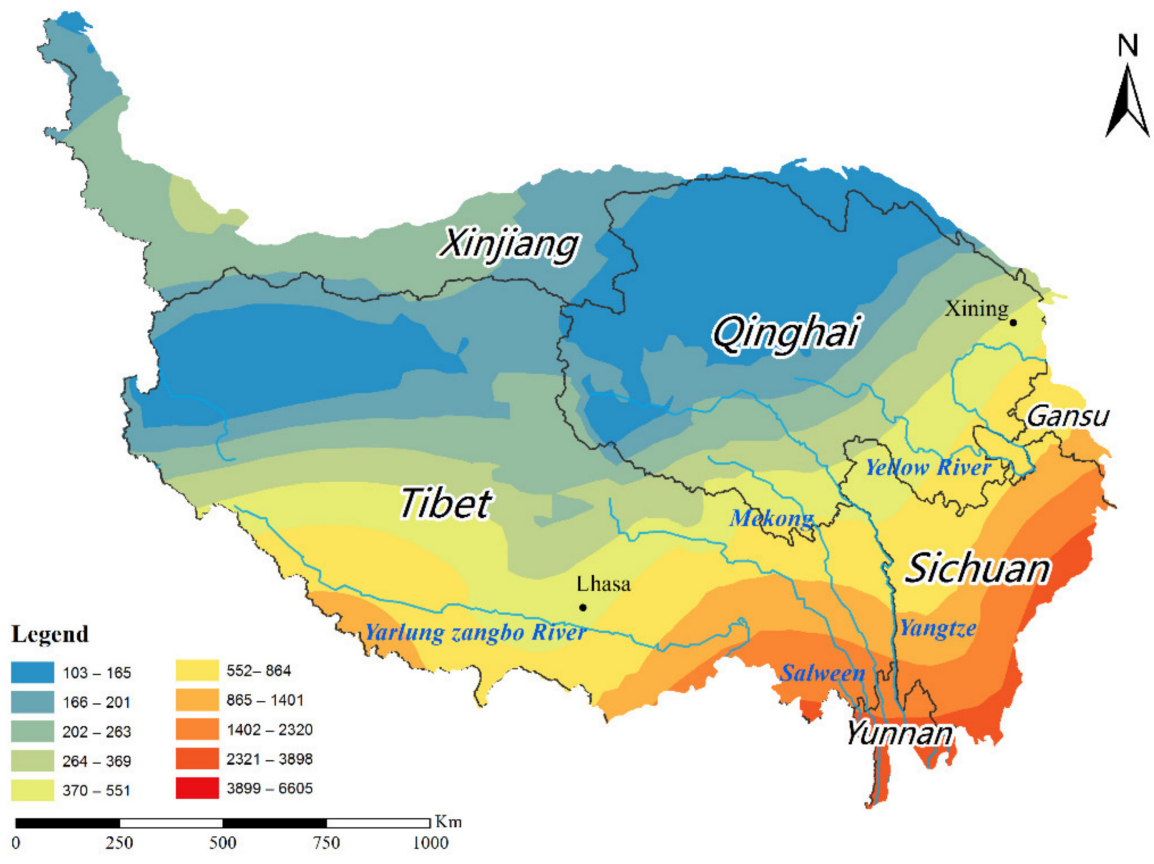

Figure 5. Spatial distribution of rainfall erosivity on the TP during the period from 1971 to 2020. 
The long time series trend analysis of each meteorological station on the TP from 1971 to 2020 showed that the annual rainfall erosivity exhibited an increasing trend at 49 meteorological stations, accounting for $54 \%$ of all stations. Thereby this demonstrated the reason for the increasing rainfall erosivity across the entire TP since 1971 (Figure S4). Of these, 13 meteorological stations increased consistently, mainly in the eastern Hengduan Mountains of the TP, accounting for $27 \%$ of the total increases. The meteorological stations that showed a pattern of rainfall erosivity increased first and then gradually stabilized were mainly located in the Hehuang valley in the northeastern part of the Tibetan Plateau and the southern Tibetan valley in the southeast, accounting for $27 \%$ of the total increase in stations. The annual rainfall erosivity showed a long-term stable (no significant trend) pattern at 37 meteorological stations, accounting for $41 \%$ of all meteorological stations. Only five stations showed a gradual decrease in annual rainfall erosivity, accounting for $5 \%$ of all meteorological stations, but both patterns of change were not significant. In addition, as shown in Table S2, further analysis based on the statistics results of the multiple indicators at each station revealed that the types of trends at each site differ significantly in terms of significance levels and magnitude of change. Of all the increasing pattern stations, the significant increases were seen at Min station $(p=0.05)$ and Derong station $(p=0.01)$. The largest and smallest increases were at Min station and Pishan station, respectively. Of all the increasing-stagnating pattern stations, there are five meteorological stations at more than $95 \%$ confidence level, namely Zekog station $(p=0.01)$, Gerze station $(p=0.01)$, Dulan station $(p=0.01)$, Wuwei station $(p=0.01)$, and Guinan station $(p=0.05)$. Of all the decreasing pattern stations, the largest and smallest increases were at Gongshan station and Artux station, respectively.

As shown in Figure 6, the mean coefficient of variation $(\mathrm{CV}$, the ratio of the standard deviation to the mean) in the interannual rainfall erosivity for 91 stations since 1971 was 0.61 , indicating moderately high rainfall erosivity variability across the plateau. The spatial distribution pattern of CV had high consistency with annual rainfall erosivity. In other words, the CV increased from south-east to north-west. Specifically, 11 meteorological stations were in regions of intense variation $(\mathrm{CV}>1)$, mostly in the north-western flank of the Kunlun Mountains on the TP, the Ali Mountains in the Tibet Autonomous Region, and the northern Qilian Mountains in eastern Qinghai Province. while 54 meteorological stations were in regions of lesser variation $(\mathrm{CV}<0.5)$, accounting for $59 \%$ of the total meteorological stations, mainly in the south-eastern part of the TP. Furthermore, the meteorological station with the smallest CV in the interannual rainfall erosivity was Jiulong Station, located in Sichuan Province in the southeastern part of the Tibetan Plateau, while the largest CV was Pishan Station, located in Xinjiang Autonomous Region in the northwestern part of the Tibetan Plateau. In summary, over the past half century, rainfall erosivity exhibited clear spatial disparities on the TP, specifically, annual rainfall erosivity in the southeast were mainly characterized by a slowly and steadily increase, while annual rainfall erosivity in the northwestern part of the plateau showed greater fluctuations and instability, with no significant trends.

The seasonal spatial distribution pattern of rainfall erosivity varied widely across the TP (Figure 7). Five meteorological stations (5.5\% of the total) with the highest percentage of spring rainfall erosivity were concentrated in the Kunlun Mountains on the Tibetan Plateau near the Pamir Plateau and in the Nu River basin in the Eastern Himalaya. In particular, the erosivity of spring rainfall accounted for more than $50 \%$ of Pishan station, Kashgar station, and Zayu station, and Pishan station was as high as 79\%. (Figure 7a). Nearly 92\% of the meteorological stations (total 84) had the highest percentage of summer rainfall erosivity. The largest was Shiquanhe station, which surprisingly had $94.28 \%$ of the annual rainfall erosivity (Figure $7 \mathrm{~b}$ ). There was only one meteorological station with the highest percentage of fall rainfall erosivity, with three stations accounting for more than 30\%, namely Nyalam, Burang, and Keriya station (Figure 7c). Winter was the season with the lowest percentage of rainfall erosivity, all stations had less than $30 \%$ of rainfall erosivity (Figure 7d). Summer and autumn were the most erosive seasons. It is worth noting that 
rainfall erosivity was generally higher across the plateau in summer, particularly in the southeastern part of the Tibetan Plateau, whereas rainfall erosivity in autumn and winter was still higher proportion in the south-western part of the plateau near the Himalayas. Thus, extra caution will be needed to prevent aggravation of soil erosion in this region.

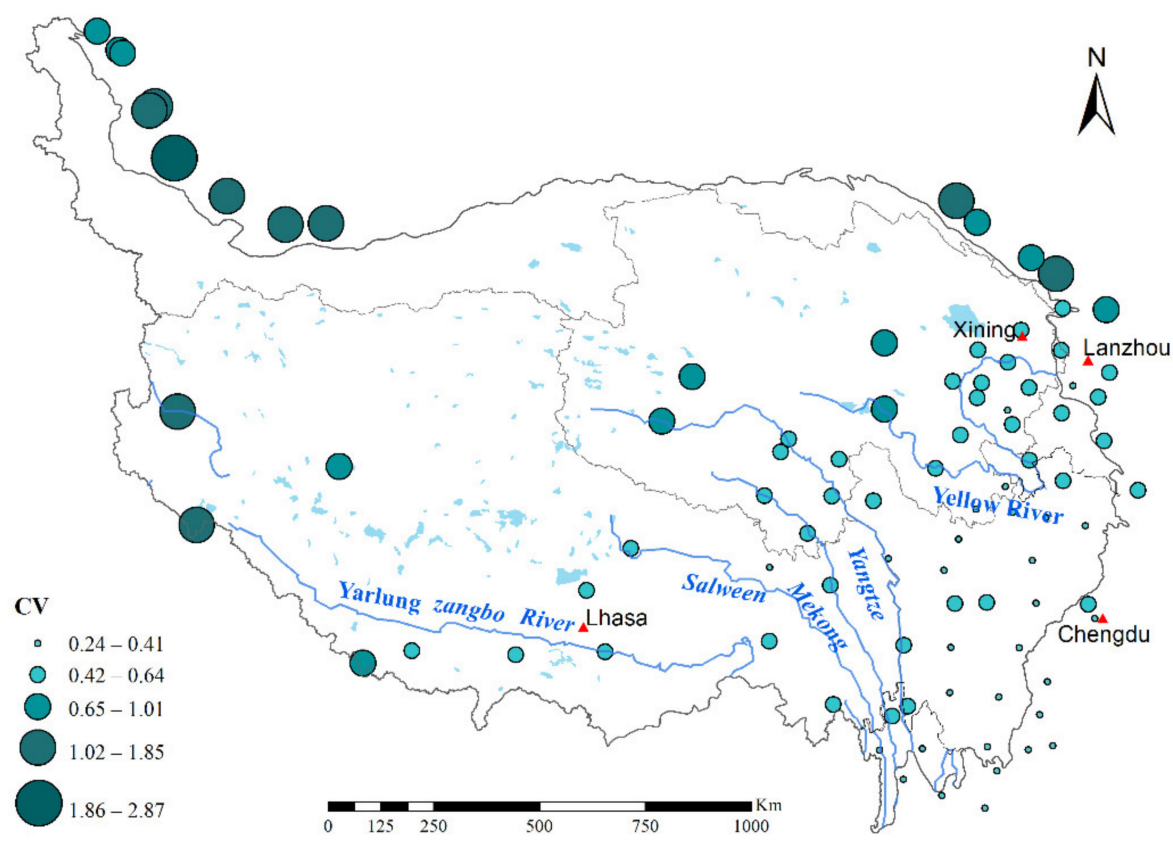

Figure 6. Spatial distribution of the coefficient of variation (CV) in rainfall erosivity during 1971-2020.
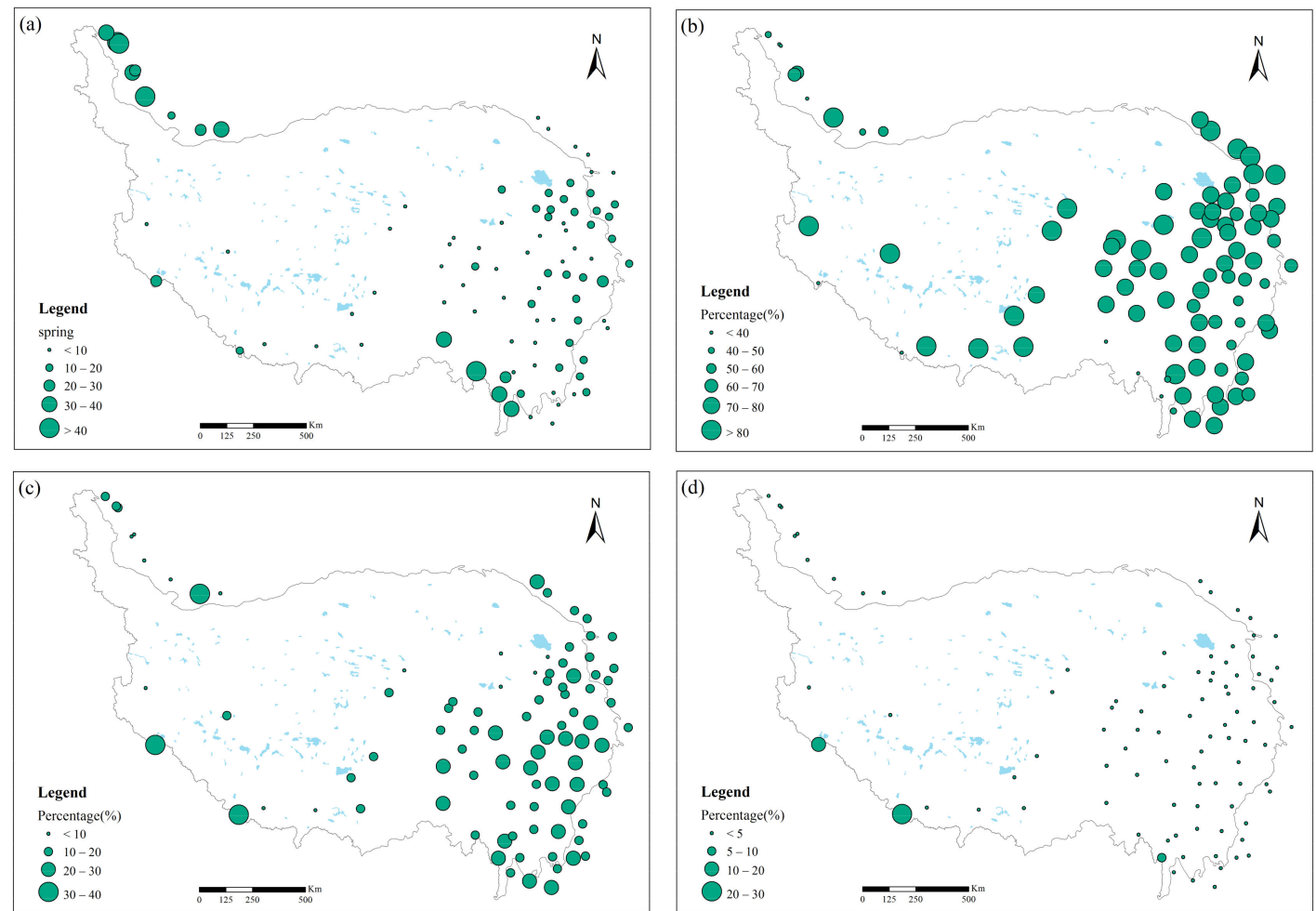

Figure 7. Spatial pattern of rainfall erosivity from 1971 to 2020 in spring (a), summer (b), autumn (c), and winter (d). Note: Percentage refers to the proportion of seasonal rainfall erosivity to total annual erosivity. 


\subsection{Relationship between Rainfall Erosivity and ENSO}

3.4.1. Influence of ENSO on Rainfall Erosivity in the Different Regions of TP

The El Niño and La Niña events are the ENSO cycles of the warm and cold periods, respectively. Statistics on the rainfall erosivity in Region I (arid zone) and Region II (humid zone) of the TP and whole plateau during the El Niño (ENSO warm event) and La Niña (ENSO cold event) periods are presented in Table 2.The occurrence and duration of El Niño event and La Niña event were determined based on ONI.

Table 2. Average monthly rainfall erosivity in different regions (Region I and Region II) and TP for El Niño and La Niña events from 1971 to 2020. The bottom table provides a summary of the average monthly rainfall erosivity.

\begin{tabular}{|c|c|c|c|c|c|}
\hline No. & Time Internal & Duration Time & Region I Erosivity & Region II Erosivity & TP Erosivity \\
\hline \multicolumn{6}{|c|}{ El Niño events } \\
\hline 1 & 1972.05-1973.03 & 11 & 282.09 & 233.00 & 201.92 \\
\hline 2 & 1976.09-1977.02 & 6 & 90.57 & 216.53 & 198.37 \\
\hline 3 & 1977.09-1978.01 & 5 & 114.40 & 132.34 & 120.58 \\
\hline 4 & 1979.10-1980.02 & 5 & 104.33 & 209.91 & 175.40 \\
\hline 5 & 1982.04-1983.06 & 15 & 83.32 & 214.03 & 174.49 \\
\hline 6 & 1986.09-1988.02 & 18 & 315.97 & 221.63 & 225.18 \\
\hline 7 & 1991.05-1992.06 & 14 & 106.09 & 256.33 & 210.08 \\
\hline 8 & 1994.09-1995.03 & 7 & 74.89 & 167.78 & 142.50 \\
\hline 9 & 1997.05-1998.05 & 13 & 144.15 & 235.53 & 193.00 \\
\hline 10 & $2002.06-2003.02$ & 9 & 141.13 & 251.03 & 208.63 \\
\hline 11 & 2004.07-2005.02 & 8 & 155.69 & 247.67 & 133.83 \\
\hline 12 & 2006.09-2007.01 & 5 & 84.40 & 167.47 & 188.51 \\
\hline 13 & $2009.07-2010.03$ & 9 & 128.03 & 217.52 & 170.04 \\
\hline 14 & 2014.10-2016.04 & 19 & 63.75 & 193.68 & 204.68 \\
\hline 15 & 2018.09-2019.06 & 10 & 318.80 & 169.55 & 201.92 \\
\hline \multicolumn{6}{|c|}{ La Niña events } \\
\hline 1 & $1971.01-1972.01$ & 12 & 105.87 & 162.81 & 142.12 \\
\hline 2 & $1973.05-1974.07$ & 15 & 101.82 & 327.52 & 197.69 \\
\hline 3 & 1974.10-1976.04 & 19 & 136.34 & 246.86 & 234.16 \\
\hline 4 & 1983.09-1984.01 & 5 & 170.46 & 216.68 & 191.36 \\
\hline 5 & 1984.10-1985.08 & 11 & 125.46 & 251.72 & 216.24 \\
\hline 6 & 1988.05-1989.05 & 13 & 408.05 & 261.23 & 486.03 \\
\hline 7 & $1995.08-1996.03$ & 8 & 117.67 & 249.63 & 190.13 \\
\hline 8 & 1998.07-2001.02 & 32 & 153.16 & 264.05 & 209.01 \\
\hline 9 & $2005.11-2006.03$ & 5 & 474.19 & 124.57 & 142.75 \\
\hline 10 & 2007.06-2008.06 & 13 & 155.75 & 201.97 & 178.10 \\
\hline 11 & $2008.11-2009.03$ & 5 & 283.13 & 123.77 & 138.83 \\
\hline 12 & $2010.06-2011.05$ & 12 & 102.80 & 214.74 & 185.26 \\
\hline 13 & 2011.07-2012.04 & 10 & 195.09 & 192.46 & 187.99 \\
\hline 14 & 2016.08-2016.12 & 5 & 109.84 & 251.42 & 223.47 \\
\hline 15 & 2017.10-2018.04 & 7 & 48.87 & 116.56 & 101.67 \\
\hline 16 & $2020.08-2020.12$ & 5 & 93.12 & 156.05 & 229.36 \\
\hline \multicolumn{3}{|c|}{ Average monthly erosivity El Niño } & 147.17 & 208.93 & 181.94 \\
\hline \multicolumn{3}{|c|}{ Average monthly erosivity La Niña } & 173.85 & 210.13 & 203.39 \\
\hline \multicolumn{3}{|c|}{ Average monthly erosivity ENSO } & 160.51 & 209.53 & 192.67 \\
\hline \multicolumn{3}{|c|}{ Average monthly erosivity non-ENSO } & 140.48 & 253.09 & 213.77 \\
\hline \multicolumn{3}{|c|}{ Average monthly erosivity $1971-2020$} & 146.25 & 233.68 & 208.12 \\
\hline
\end{tabular}

In terms of the degree of influence of cold and warm events on the rainfall erosivity, the average monthly rainfall erosivity for the El Niño event was slightly lower than the La Niña event across the TP, but the average of both events was less than the monthly rainfall erosivity for the period 1971-2020. During the El Niño event, the maximum monthly average rainfall erosivity was $225.18 \mathrm{MJ} \cdot \mathrm{mm} \cdot \mathrm{ha}^{-1} \cdot \mathrm{h}^{-1}$ and the minimum value was $120.58 \mathrm{MJ} \cdot \mathrm{mm} \cdot \mathrm{ha}^{-1} \cdot \mathrm{h}^{-1}$, with an extreme value ratio of 1.87 ; during the La Niña event, the maximum monthly average rainfall erosivity was $486.03 \mathrm{MJ} \cdot \mathrm{mm} \cdot \mathrm{ha}^{-1} \cdot \mathrm{h}^{-1}$ and the 
minimum value was $101.67 \mathrm{MJ} \cdot \mathrm{mm} \cdot \mathrm{ha}^{-1} \cdot \mathrm{h}^{-1}$, with an extreme value ratio of 4.78 ; thus, higher variability occurred during the La Niña event. In terms of the presence or absence of ENSO events, the average rainfall erosivity during the ENSO and Non-ENSO periods were 192.67 MJ.mm $\cdot \mathrm{ha}^{-1} \cdot \mathrm{h}^{-1}$ and $213.77 \mathrm{MJ} \cdot \mathrm{mm} \cdot \mathrm{ha}^{-1} \cdot \mathrm{h}^{-1}$, respectively. It was evident that the average monthly rainfall erosivity during the non-ENSO period was not only greater than that during the ENSO period, but also greater than the total average monthly rainfall erosivity for the whole study period.

The impact of ENSO events on the monthly mean rainfall erosivity in different regions was notably dissimilar. For Region I, the average monthly rainfall erosivity for the El Niño and La Niña events were $147.17 \mathrm{MJ} \cdot \mathrm{mm} \cdot \mathrm{ha}^{-1} \cdot \mathrm{h}^{-1}$ and $173.85 \mathrm{MJ} \cdot \mathrm{mm} \cdot \mathrm{ha}{ }^{-1} \cdot \mathrm{h}^{-1}$, respectively. This was higher than the average monthly rainfall erosivity for this region for 1971-2020. Moreover, we found that when El Niño events or La Niña events occurred, there was a significant increase in rainfall erosivity in Region I relative to the Non-ENSO period, but La Niña events had a greater impact on the monthly average rainfall erosivity, compared with El Niño events; For Region II, the average monthly rainfall erosivity for the El Niño and La Niña events were $208.93 \mathrm{MJ} \cdot \mathrm{mm} \cdot \mathrm{ha}^{-1} \cdot \mathrm{h}^{-1}$ and $210.13 \mathrm{MJ} \cdot \mathrm{mm} \cdot \mathrm{ha}^{-1} \cdot \mathrm{h}^{-1}$, respectively, with the El Niño event slightly lower than the La Niña event. There was a modest gap between the two events. However, compared with Region I, the direction of influence of ENSO in Region II was in the opposite direction. In other words, when ENSO occurs, the average monthly rainfall erosivity in this region decreased more significantly than the average for the study period. Due to the difference in the magnitude of rainfall erosivity on the Tibetan Plateau during the ENSO period and the non-ENSO period, under the premise that other contributing factors was fixed, rainfall erosivity was stronger during the non-ENSO period and soil erosion concerns and soil conservation measures should be strengthened during this period. Considering the obvious spatial heterogeneity of the impact of ENSO on the Tibetan Plateau, the emphasis should be on erosion in the north-west during El Niño or La Niña events, especially during the La Niña event when control measures should be enhanced.

\subsubsection{Correlation between Rainfall Erosivity and Multivariate ENSO Index}

To examine the extent and impact of ENSO on rainfall erosivity, an XWT and WTC analysis were conducted on the time series of rainfall erosivity and MEI index in different regions of the Tibetan Plateau from 1971 to 2020, revealing the periodicity characteristics of both. As shown in Figure 8, in the time-frequency space domain of Region I, it is obvious that there was 3-5 years of high-energy resonance cycle between rainfall erosivity and the MEI index for the period of 1981-1988, during which there was a negative correlation between both time series. In the Region II power spectrum, there were two significant high-energy domains, specifically a 3-5 years resonance cycle from 1981 to 1988 was similar to that of Region I, indicating a consistent ENSO effect across the plateau during this period, but the intensity of the Region II resonance cycle was higher. The other was that there was a 2-5 years resonance cycle of rainfall erosivity and the MEI index from 1995 to 1999, and the mean phase angle was nearly $90^{\circ}$ vertically upwards, indicating that the rainfall erosivity change was later than the MEI index. In other words, rainfall erosivity had a lag compared with ENSO over the same period. As shown in Figure 9, in the Region I WTC power spectrum, there were negative phase cycles of 3-5 years and 2-3 years in 1985-1992 and 2006-2009, respectively, indicating a negative correlation between rainfall erosivity and the MEI index during this period. Regarding Region II, there were negative phase cycles of 3-7 years from 1977 to 1988, 1-3 years from 1994 to 1998 and 2-4 years from 2007 to 2013 , indicating a negative correlation between rainfall erosivity and the MEI index during these periods. While positive phase cycles of 1-2 years from 1987 to 1989 indicate a positive correlation between rainfall erosivity and the MEI index during this period. 


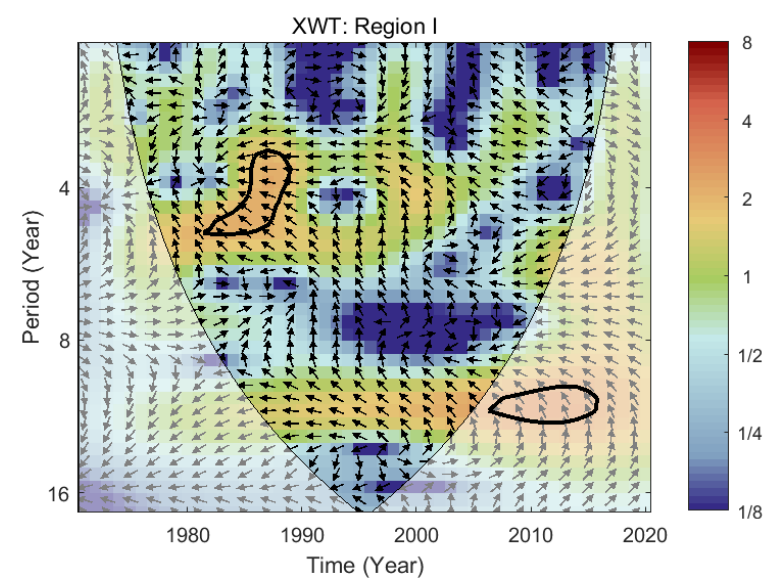

(a)

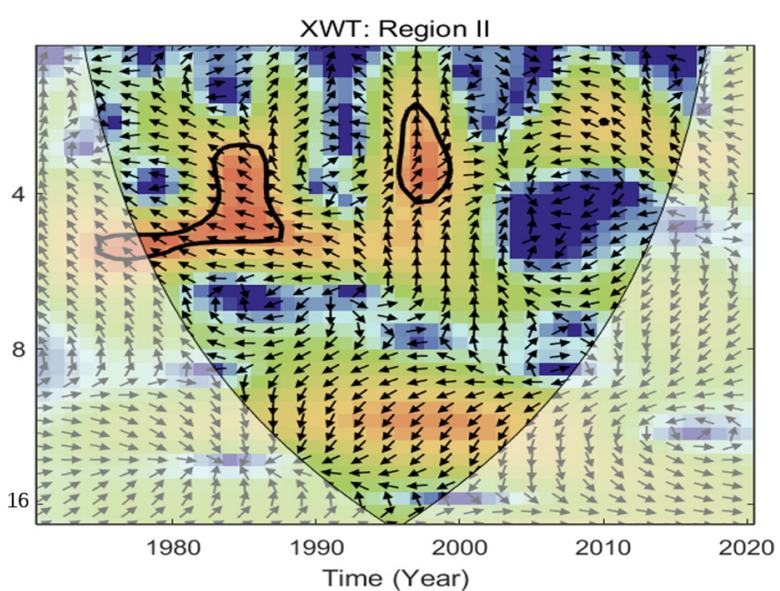

(b)

Figure 8. Cross wavelet transforms (XWTs) for annual rainfall erosivity and multivariate ENSO Index (MEI) in Region I (a) and Region II (b). NOTE: The thick black outline indicates the 95\% significance level against red noise, the white translucent area indicates the cone of influence, and the color bar indicates the magnitude of the XWT cross spectral power. That is, red is strong and blue is weak. The arrows (vectors) designate the phase difference between rainfall erosivity and MEI. Where the left arrow indicates the opposite phase relationship between the rainfall erosivity and MEI and vice versa. The north-pointing arrow indicates that the peak rainfall erosivity are lower than the peak MEI.

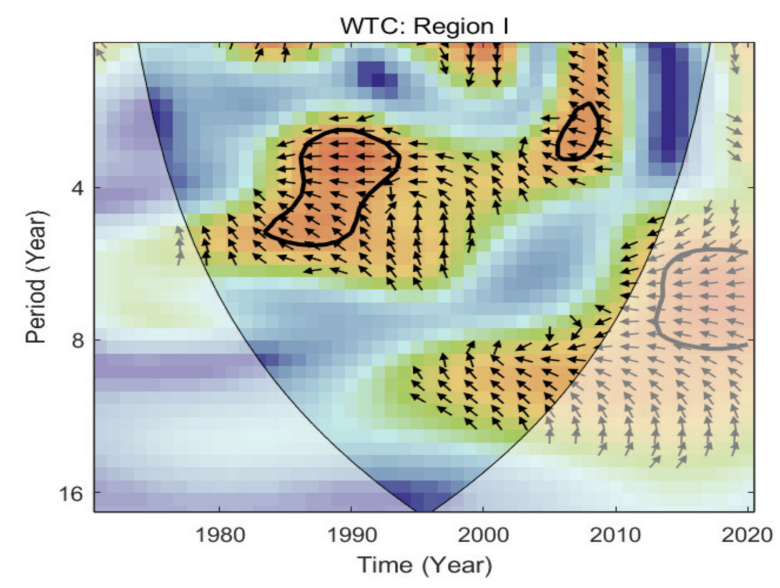

(a)

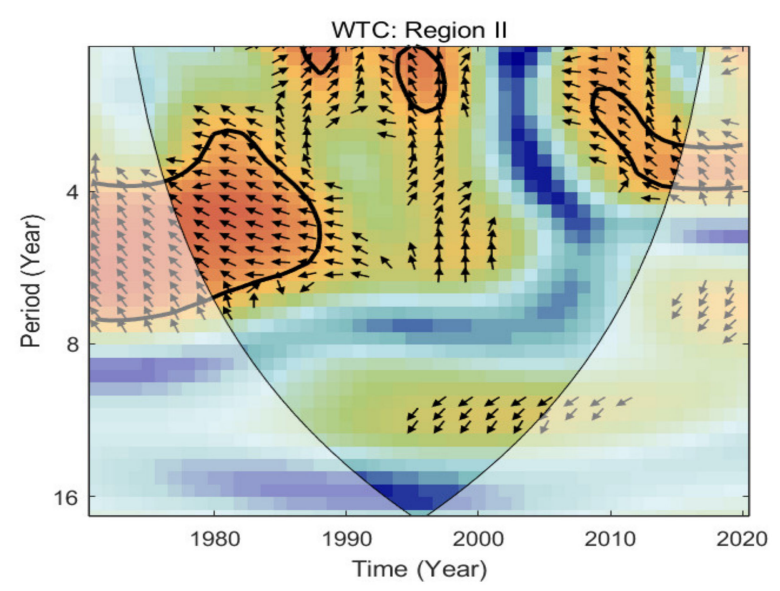

(b)

Figure 9. Wavelet transform coherence (WTC) for annual rainfall erosivity and multivariate ENSO Index (MEI) in Region I (a) and Region II (b). NOTE: The thick black outline indicates the 95\% significance level, the white translucent area indicates the cone of influence, and the color bar indicates the significance level of the Monte Carlo test. That is, red means strong correction and blue is weak. where the left arrow indicates the opposite phase relationship between the two-time series, vice versa.

\section{Discussion}

This study revealed the spatial and temporal characteristics of rainfall erosivity on the TP from 1971 to 2020 and their relationship with the ENSO Index. The results showed that the average annual rainfall erosivity on the TP since 1971 was $1071.42 \mathrm{MJ} \cdot \mathrm{mm} \cdot \mathrm{ha}^{-1} \cdot \mathrm{h}^{-1}$. According to previous studies, this value is higher than in northwestern China but lower than in southeastern China [74], and the overall degree of erosion is light, approximately 0.5 times the global average [91]. Upward trends are shown for rainfall erosivity during 1971 to 2020. Gu et al. also found an increasing trend in rainfall erosivity from 1981 to 2015 in the Tibet Autonomous Region (TAR) [60], and Wang et al. found a same uptrend in rainfall-runoff erosivity from 1961 to 2012 in Sanjiangyuan region, Qinghai Province [53], which is consistent with this study. Fan et al. [61] used TRMM 3B42 data to assess the 
spatial and temporal variability of rainfall erosivity in the TAR from 2000 to 2010 and found that the average rainfall erosivity was $768 \mathrm{MJ} \cdot \mathrm{mm} \cdot \mathrm{ha}^{-1} \cdot \mathrm{h}^{-1}$, which is lower than the results of this study, probably due to the different extent of the study area and the accuracy of the data. Moreover, the reasons for the trend of increasing annual rainfall erosivity but significant decreasing rainfall erosivity in spring and autumn may be related to the variation in rainfall on the TP [92]. Previous studies have shown that since 1961, the Tibetan Plateau is gradually warming and humidifying [93], which may contribute to an increase in rainfall erosivity. Meanwhile, while changes in the westerly circulation lead to a reduction in rainfall in spring and autumn which in turn affects rainfall erosivity [94].

In the previous section, this work indicated rainfall erosivity on the TP varied greatly not only seasonally but also monthly. This may be caused by its complicated geography and dominant atmospheric circulation conditions [95]. The plateau spans a wide range of latitudes and longitudes and has a variety of climate types. It is also at the crossroads of monsoon and non-monsoon zones, and is influenced by the prevailing westerly winds, the South Asian monsoon and the East Asian monsoon circulation, resulting in an uneven spatial and temporal distribution of rainfall. Besides, according to previous reports, the amount and intensity of rainfall are the main factors affecting the rainfall erosivity [96]. The spatial and temporal variability of rainfall at various magnitudes will certainly contribute to soil erosion by water at different times and regions to different degrees [97,98]. The average heavy rainfall and average heavy rainfall erosivity for each station from 1971 to 2020 are presented in Table S3. It can be seen from Table S3 that the average heavy rainfall ( $\geq 25 \mathrm{~mm}$ ) of 91 meteorological stations in the plateau was $33.05 \mathrm{~mm}$, and the average rainfall erosivity was $243.35 \mathrm{MJ} \cdot \mathrm{mm} \cdot \mathrm{ha}^{-1} \cdot \mathrm{h}^{-1}$. The absolute amount of erosivity caused by heavy rainfall on the TP is low compared with the eastern coastal areas of China, mainly because the total rainfall erosivity in the plateau is much lower than those in the east $[35,99,100]$. Furthermore, the comparison of the proportion of heavy rain and rainfall erosivity found that the average heavy rainfall on the TP accounted for only $27.02 \%$ of the total rainfall, but the rainfall erosivity caused by heavy rainfall occupied by $43.3 \%$ of the total rainfall erosivity (Figure 10). In addition, the change in the percentage of heavy rainfall and heavy rainfall erosivity has a high consistency on the TP. In case of heavy rainfall, it can be easily seen that rain erosivity becomes more intense. The maximum values of heavy rainfall and heavy rainfall erosivity were $71.26 \%$ and $81.46 \%$, respectively, both of which occurred at Dujiangyan station, and the minimum values of $6.77 \%$ and $8.15 \%$, respectively, which occurred at Zhidoi station. Studies have revealed that rainfall is the most important climatic factor contributing to soil erosion, and in particular, heavy rainfall ( $\geq 25 \mathrm{~mm})$ is one of the main factors affecting the rainfall erosivity [101]. In general, the higher the intensity of the heavy rainfall, the greater the amount of soil erosion. The frequency of extreme rainfall events is growing as a result of global climate change [102,103], Future research should pay more attention to high intensity rainfall and soil erosion.

The spatial distribution of rainfall erosivity on the TP decreased roughly from southeast to north-west, with significant spatial heterogeneity. Previous studies have shown that mountain tectonics and topographic gradients are essential factors influencing precipitation [104]. The high rainfall erosivity in the south-east is largely attributed to the roughly north-south alignment of the Hengduan Mountains and the gradual rise in elevation from south to north, which is a natural water vapor corridor and facilitates the deeper uplift of monsoon air masses and the formation of rainfall. The north-west of the plateau, on the other hand, is located in an inland region, with high altitude and low temperatures. It is extremely hard for the monsoon to reach it, and rainfall is minimal throughout the year, resulting in lower rainfall erosivity. Besides, in the southern part of the plateau, although it is on the leeward slopes of the Himalayas, where water vapor is not easily accessible, the Yarlung Tsangpo valley is at a relatively low altitude and has locally better hydrothermal conditions, resulting in a higher rainfall erosivity in the region. In addition, the role of anthropogenic activities should not be neglected. Nearly $38.8 \%$ of the grasslands on the TP have been degraded [105], and the degradation of meadows caused by overgrazing is a 
serious environmental and ecological problem. Consequently, soil erosion caused by the contradiction between people and land may exacerbate the rainfall erosivity.

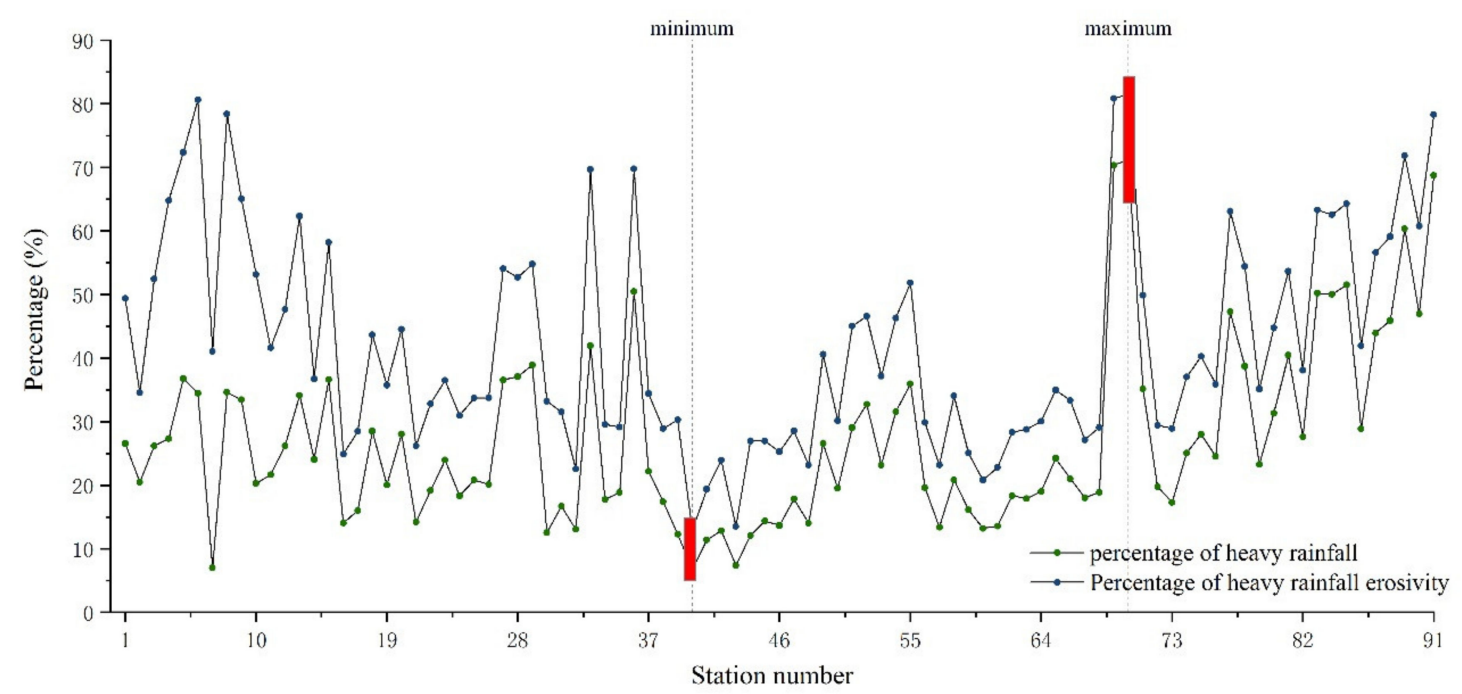

Figure 10. Comparison of the proportion of heavy rain (daily rainfall $\geq 25 \mathrm{~mm}$ ) and rainfall erosivity for 91 meteorological stations on the TP from 1971 to 2020. Note: the designation of station numbers is shown in Table S3; and the percentage of heavy rainfall represents the proportion of heavy rain amount to total annual precipitation; percentage of heavy rainfall erosivity represents the proportion of heavy rainfall erosivity to annual rainfall erosivity.

Clarifying the temporal and spatial patterns of rainfall erosivity on the TP over the past 50 years is of great significance for soil conservation and future land use planning. This paper indicates that the tendency of increasing rainfall erosivity was identified in the southeastern part of the TP. Published studies have shown that the Hengduan Mountains region has the highest soil erosion modulus of the TP [106]. Furthermore, the alternation of steep slopes and deep ravines, the superimposed effect of complex topography and intensified rainfall erosivity may further magnify soil erosion in this region. The Yarlung Tsangpo Valley and the Hehuang Valley are areas of intensive human activity on the TP, and are also major wheat and barley cultivation areas, with crops mostly grown on the slopes of the valleys [107]. Although rainfall erosivity has not shown a sharp rise over the past 50 years in these origins, the region's originally high rainfall erosivity may still result in frequent natural hazards and elevated ecological risks. The deployment of measures against landslides and debris flows should be considered as a priority. In the western and northern parts of the Tibetan Plateau, there is higher variability, although with lower rainfall erosivity. On the one hand, in the context of increased rainfall erosivity across the plateau, it is still possible to damage the low-cover turf. In particular, the interactive effects of human activities such as grazing and soil erosion processes can also exacerbate the 'black beach' degradation of plateau grasslands. On the other hand, the north-west has a higher altitude and fragile natural environment where seasonal differences in rainfall erosivity is more likely to cause damage to alpine ecosystems. Therefore, soil erosion management strategies in this region should not be neglected either.

The impact of global-scale climate oscillation regimes on climate change has received widespread attention. This paper used MEI to characterize the global-scale climate oscillation model ENSO in an attempt to explore the relationship between ENSO and rainfall erosivity on the Tibetan Plateau, with a view to providing guidance for collaborative work on climate change and soil conservation. This study found that rainfall erosivity was lower during ENSO than during non-ENSO, and other studies have found the same results $[35,36]$. ENSO is a major factor influencing temperature and precipitation in China. Some studies have shown that precipitation anomalies can reach up to $30 \%$ of the average precipitation during ENSO periods [108]. It is worth noting that rainfall erosivity was 
higher during the La Niña period than during the El Niño period on the TP. This is not in agreement with previous studies, with results in places such as Fujian in southeastern China [37], but is consistent with studies in Guizhou in southwestern China [36]. The other research indicated that El Niño occurs with a delayed arrival of the southwest monsoon, while the opposite occurs at La Niña, so this may be related to a weakening of the Indian monsoon $[109,110]$. These findings would explain the difference of rainfall erosivity between the La Niña period and El Niño period. According to the CWT results, a noticeable resonance cycle between rainfall erosivity and MEI was found in different regions of the Tibetan Plateau, but there were also significant differences in cycle duration, direction of action, and intensity. This may be due to the fact that ENSO events themselves present diversities of climatic features at each stage of occurrence, development, maturation and decline [108]. Additionally, it also suggested that global climate anomalies are an important driver of changes in the rainfall erosivity on the TP.

Due to the vast expanses of land and sparse populations as well as the harsh natural conditions, the distribution of weather stations on the Tibetan Plateau is extremely irregular, which may affect the accuracy of the interpolation. Although this study improves the comprehension of the impact of ENSO on rainfall erosivity, it still lacks further explanation from a mechanistic perspective. Furthermore, in light of the known results, it is clear that not only ENSO but also topography, altitude, and microclimate are associated with rainfall erosivity, and detailed knowledge will be necessary for future studies.

\section{Conclusions}

This study carried out an insightful analysis of the spatial, interannual, and seasonal variability of rainfall erosivity on the TP from 1971 to 2020 and its relationship with ENSO. Daily rainfall data from 91 meteorological stations were collected, and the change trend of rainfall erosivity calculated based on a daily rainfall erosivity model were detected at a regional and site-scale using methods such as Mann-Kendall test and Sen's slope. The potential influence of ENSO on rainfall erosivity was revealed using the continuous wavelet transform method. The main findings were summarized below:

Rainfall erosivity has shown a fluctuating trend of increasing over the past half century. Seasonal and monthly rainfall erosivity showed high heterogeneity, which was greatly related to heavy rainfall. The rainfall erosivity in order was summer $>$ autumn $>$ spring $>$ winter. July was the most erosive month, accounting for $24.19 \%$ of the year, while November was the lowest, accounting for only $1.12 \%$. The rainfall erosivity in spring and autumn showed a significant decreasing trend $(p<0.05)$, and in summer it showed an increasing trend but not significant. There was generally an obvious spatial variation in rainfall erosivity on the TP from 1971 to 2020, presenting a roughly spatial pattern of decreasing distribution from southeast to northwest. Annual rainfall erosivity in the south-eastern part of the plateau was mainly characterized by a slow increase, while in the north-western part annual rainfall erosivity was more unstable with mostly no significant trends.

ENSO events had a significant impact on rainfall erosivity on the TP. The rainfall erosivity in the non-ENSO period was higher than that in the ENSO period, and the La Niña event was higher than the El Niño event. It was also found that there was a clear resonance cycle between rainfall erosivity and ENSO in different regions of the plateau, with an average cycle of about 3-5 years in the high energy region, but there were differences in the timing of occurrence, direction of action, and intensity of the cycle. The rainfall erosivity on the TP was relatively large during non-ENSO periods and relatively small during El Niño/La Niña periods. In addition, the response of rainfall erosivity to ENSO was spatially heterogeneous. Rainfall erosivity in the northwest of TP appears to be more serious during the La Niña event and less severe during the El Niño event. It can be concluded that soil erosion may become more intense during the La Niña event in the northwest TP. Therefore, during the La Niña event, soil protection should be enhanced to diminish soil spattering and disturbance. 
This study contributes to the understanding of the spatial and temporal variability of annual rainfall erosivity across the entire TP over the last half century and extends the cognition of the possible impact of changes in ENSO characteristics associated with climate change. Uncertainties may be involved due to limited data availability and interpolation bias errors. Future studies should integrate the effects of multiple factors on rainfall erosivity, more carefully relate the effects of climate extremes, and improve the insights from the mechanistic aspects of change.

Supplementary Materials: The following are available online at https:/ /www.mdpi.com/article/10 .3390/ijerph182111054/s1, Figure S1: Rainfall erosivity anomalies from 1971 to 2017, the blue line shows the 5-year moving average curve, Figure S2: Sequential MK test for 50-year rainfall erosivity of TP. Note: UF and UB refer to progressive and retrograde sequences within the sequence, respectively. $\mathrm{UF}>0$ indicates an increasing trend, $\mathrm{UF}<0$ indicates a decreasing trend. The mutation year exists at the intersection of UF and UB. The dashed line represents the $95 \%$ confidence interval, Figure S3: Seasonal and monthly average rainfall erosivity Mann-Kendall trends of plateau from 1971 to 2020. ${ }^{* *} p<0.01 ; * p<0.05 ;+p<0.1$, Figure S4: Long-term trend pattern of rainfall erosivity at each station from 1971 to 2020. Note: DE: decreasing, ST: stagnating, IN-ST: increasing-stagnating, IN: increasing, Table S1: The basic information of 91 meteorological stations in this study. 'No' refers to station number, which is the same as the station number in Figure 1, Table S2: Statistical results of Z, SLOPE, and $R_{s t}$ associated with the rainfall erosivity trend classification at each meteorological station on the TP from 1971 to 2020, Table S3: The average heavy rainfall (AHR) and its proportion (HR) and the proportion of average heavy rain erosivity (HRE) of each station from 1971 to 2020.

Author Contributions: Y.Z. and B.C. had the original idea and designed the study. B.C. processed and analyzed the data and wrote the manuscript; Y.Z., L.L. and Z.W. had insights on the revision of the manuscript and suggestions for improvement. Z.X. provided help and guidance for data processing and model adjustment. C.G., B.W. and D.G. revised the paper and polished the language. All authors have read and agreed to the published version of the manuscript.

Funding: This research was funded by the Strategic Priority Research Program of the Chinese Academy of Sciences (Grant No. XDA20040201), the Second Tibetan Plateau Scientific Expedition and Research (Grant No. 2019QZKK0603), and the National Natural Science Foundation of China (Grant No. 41671104).

Institutional Review Board Statement: Not applicable.

Informed Consent Statement: Not applicable.

Data Availability Statement: All relevant data sets in this study are described in the manuscript.

Conflicts of Interest: The authors declare no conflict of interest.

$\begin{array}{ll}\text { Abbreviations } \\ \text { ENSO } & \text { El Niño southern oscillation } \\ \text { TP } & \text { Tibetan Plateau } \\ \text { ONI } & \text { Oceanic Niño Index } \\ \text { MEI } & \text { Multivariate ENSO Index } \\ \text { CWT } & \text { Continuous wavelet transforms } \\ \text { XWT } & \text { Cross Wavelet Transform } \\ \text { WTC } & \text { Wavelet Transform Coherence } \\ \text { CV } & \text { Coefficient of variation }\end{array}$

\section{References}

1. Amundson, R.; Berhe, A.A.; Hopmans, J.W.; Olson, C.; Sztein, A.E.; Sparks, D.L. Soil and human security in the 21st century. Science 2015, 348. [CrossRef] [PubMed]

2. Pimentel, D.; Kounang, N. Ecology of soil erosion in ecosystems. Ecosystems 1998, 1, 416-426. [CrossRef]

3. Lal, R.; Bruce, J.P. The potential of world cropland soils to sequester C and mitigate the greenhouse effect. Environ. Sci. Policy 1999, 2, 177-185. [CrossRef] 
4. Pimentel, D.; Harvey, C.; Resosudarmo, P.; Sinclair, K.; Kurz, D.; McNair, M.; Crist, S.; Shpritz, L.; Fitton, L.; Saffouri, R.; et al. Environmental and economic costs of soil erosion and conservation benefits. Science 1995, 267, 1117-1123. [CrossRef] [PubMed]

5. Borrelli, P.; Robinson, D.A.; Panagos, P.; Lugato, E.; Yang, J.E.; Alewell, C.; Wuepper, D.; Montanarella, L.; Ballabio, C. Land use and climate change impacts on global soil erosion by water (2015-2070). Proc. Natl. Acad. Sci. USA 2020, 117, 21994-22001. [CrossRef] [PubMed]

6. Panagos, P.; Borrelli, P.; Poesen, J.; Ballabio, C.; Lugato, E.; Meusburger, K.; Montanarella, L.; Alewell, C. The new assessment of soil loss by water erosion in Europe. Environ. Sci. Policy 2015, 54, 438-447. [CrossRef]

7. Blanco, H.; Lal, R. Principles of Soil Conservation and Management; Springer: New York, NY, USA, $2008 ;$ p. 167169.

8. Montgomery, D.R. Soil erosion and agricultural sustainability. Proc. Natl. Acad. Sci. USA 2007, 104, 13268-13272. [CrossRef]

9. Acquaotta, F.; Faccini, F.; Fratianni, S.; Paliaga, G.; Sacchini, A.; Vil I Mek, V.I.T. Increased flash flooding in Genoa Metropolitan Area: A combination of climate changes and soil consumption? Meteorol. Atmos. Phys. 2019, 131, 1099-1110. [CrossRef]

10. Pennock, D.J. Soil Erosion: The Greatest Challenge for Sustainable Soil Management; Food and Agriculture Organization of the United Nations: Rome, Italy, 2019.

11. Li, Z.; Fang, H. Impacts of climate change on water erosion: A review. Earth-Sci. Rev. 2016, 163, 94-117. [CrossRef]

12. Renard, K.G. Predicting Soil Erosion by Water: A Guide to Conservation Planning with the Revised Universal Soil Loss Equation (RUSLE); United States Government Printing: Washington DC, USA, 1997.

13. Wischmeier, W.H.; Smith, D.D. Predicting rainfall-erosion losses from cropland east of the Rocky Mountains; No. 282; US Department of Agriculture, Government Printing Office: Washington, DC, USA, 1965.

14. Diodato, N. Estimating RUSLE's rainfall factor in the part of Italy with a Mediterranean rainfall regime. Hydrol. Earth Syst. Sci. 2004, 8, 103-107. [CrossRef]

15. Bonilla, C.A.; Vidal, K.L. Rainfall erosivity in central Chile. J. Hydrol. 2011, 410, 126-133. [CrossRef]

16. Lee, J.; Heo, J. Evaluation of estimation methods for rainfall erosivity based on annual precipitation in Korea. J. Hydrol. 2011, 409, 30-48. [CrossRef]

17. De Santos Loureiro, N.; de Azevedo Coutinho, M. A new procedure to estimate the RUSLE EI30 index, based on monthly rainfall data and applied to the Algarve region, Portugal. J. Hydrol. 2001, 250, 12-18. [CrossRef]

18. Renard, K.G.; Freimund, J.R. Using monthly precipitation data to estimate the R-factor in the revised USLE. J. Hydrol. 1994, 157, 287-306. [CrossRef]

19. Angulo-Martínez, M.; Beguería, S. Estimating rainfall erosivity from daily precipitation records: A comparison among methods using data from the Ebro Basin (NE Spain). J. Hydrol. 2009, 379, 111-121. [CrossRef]

20. Zhang, W.; Xie, Y.; Liu, B. Rainfall erosivity estimation using daily rainfall amounts. Sci. Geogr. Sin. 2002, 22, 705-711.

21. Chen, Y.; Xu, M.; Wang, Z.; Gao, P.; Lai, C. Applicability of two satellite-based precipitation products for assessing rainfall erosivity in China. Sci. Total Environ. 2021, 757, 143975. [CrossRef] [PubMed]

22. Teng, H.; Ma, Z.; Chappell, A.; Shi, Z.; Liang, Z.; Yu, W. Improving rainfall erosivity estimates using merged TRMM and gauge data. Remote Sens. 2017, 9, 1134. [CrossRef]

23. Liu, B.T.; Tao, H.P.; Song, C.F.; Guo, B.; Shi, Z.; Zhang, C.; Kong, B.; He, B. Temporal and spatial variations of rainfall erosivity in China during 1960 to 2009. Geogr. Res. 2013, 32, 245-256.

24. Mello, C.D.; Viola, M.R.; Beskow, S.; Norton, L.D. Multivariate models for annual rainfall erosivity in Brazil. Geoderma 2013, 202, 88-102. [CrossRef]

25. De Luis, M.; Gonz A Lez-Hidalgo, J.C.; Longares, L.A. Is rainfall erosivity increasing in the Mediterranean Iberian Peninsula? Land Degrad. Dev. 2010, 21, 139-144. [CrossRef]

26. Yu, B.; Hashim, G.M.; Eusof, Z. Estimating the R-factor with limited rainfall data: A case study from peninsular Malaysia. J. Soil Water Conserv. 2001, 56, 101-105.

27. Easterling, D.R.; Evans, J.L.; Groisman, P.Y.; Karl, T.R.; Kunkel, K.E.; Ambenje, P. Observed variability and trends in extreme climate events: A brief review. Bull. Am. Meteorol. Soc. 2000, 81, 417-426. [CrossRef]

28. Diaz, H.F. El Niño and the Southern Oscillation: Multiscale Variability and Global and Regional Impacts; Cambridge University Press: Cambridge, UK, 2000.

29. McGregor, G.R.; Ebi, K. El Niño Southern Oscillation (ENSO) and health: An overview for climate and health researchers. Atmosphere 2018, 9, 282. [CrossRef]

30. Dong, B.; Sutton, R.T.; Scaife, A.A. Multidecadal modulation of El Niño-Southern Oscillation (ENSO) variance by Atlantic Ocean sea surface temperatures. Geophys. Res. Lett. 2006, 33. [CrossRef]

31. Adams, R.M.; Houston, L.L.; McCarl, B.A.; Tiscare N O., M.; Matus, J.; Weiher, R.F. The benefits to Mexican agriculture of an El Niño-southern oscillation (ENSO) early warning system. Agr. For. Meteorol. 2003, 115, 183-194. [CrossRef]

32. Ropelewski, C.F.; Halpert, M.S. North American precipitation and temperature patterns associated with the El Niño/Southern Oscillation (ENSO). Mon. Weather Rev. 1986, 114, 2352-2362. [CrossRef]

33. Lu, B.; Li, H.; Wu, J.; Zhang, T.; Liu, J.; Liu, B.; Chen, Y.; Baishan, J. Impact of El Niño and Southern Oscillation on the summer precipitation over Northwest China. Atmos. Sci. Lett. 2019, 20, e928. [CrossRef]

34. Xu, Z.X.; Takeuchi, K.; Ishidaira, H. Correlation between El Niño-Southern Oscillation (ENSO) and precipitation in South-east Asia and the Pacific region. Hydrol. Process. 2004, 18, 107-123. [CrossRef] 
35. Xu, Z.; Pan, B.; Han, M.; Zhu, J.; Tian, L. Spatial-temporal distribution of rainfall erosivity, erosivity density and correlation with El Niño-Southern Oscillation in the Huaihe River Basin, China. Ecol. Inf. 2019, 52, 14-25. [CrossRef]

36. Zhu, D.; Xiong, K.; Xiao, H.; Gu, X. Variation characteristics of rainfall erosivity in Guizhou Province and the correlation with the El Niño Southern Oscillation. Sci. Total Environ. 2019, 691, 835-847. [CrossRef] [PubMed]

37. Chen, S.; Zha, X. Effects of the ENSO on rainfall erosivity in the Fujian Province of southeast China. Sci. Total Environ. 2018, 621, 1378-1388. [CrossRef] [PubMed]

38. Romero, C.C.; Baigorria, G.A.; Stroosnijder, L. Changes of erosive rainfall for El Niño and La Niña years in the northern Andean highlands of Peru. Clim. Chang. 2007, 85, 343-356. [CrossRef]

39. Lee, J.H.; Lee, J.; Julien, P.Y. Global climate teleconnection with rainfall erosivity in South Korea. Catena 2018, 167, 28-43. [CrossRef]

40. Angulo-Mart I Nez, M.; Beguer I A., S. Do atmospheric teleconnection patterns influence rainfall erosivity? A study of NAO, MO and WeMO in NE Spain, 1955-2006. J. Hydrol. 2012, 450, 168-179. [CrossRef]

41. D'Odorico, P.; Yoo, J.C.; Over, T.M. An assessment of ENSO-induced patterns of rainfall erosivity in the southwestern United States. J. Clim. 2001, 14, 4230-4242. [CrossRef]

42. Yao, T.; Thompson, L.G.; Mosbrugger, V.; Zhang, F.; Ma, Y.; Luo, T.; Xu, B.; Yang, X.; Joswiak, D.R.; Wang, W.; et al. Third pole environment (TPE). Environ. Dev. 2012, 3, 52-64. [CrossRef]

43. Chen, D.; Xu, B.; Yao, T.; Guo, Z.; Cui, P.; Chen, F.; Zhang, R.; Zhang, X.; Zhang, Y.; Fan, J.; et al. Assessment of past, present and future environmental changes on the Tibetan Plateau. Chin. Sci. Bull. 2015, 60, 3025-3035.

44. Yuan, Q.; Yuan, Q.; Ren, P. Coupled effect of climate change and human activities on the restoration/degradation of the Qinghai-Tibet Plateau grassland. J. Geogr. Sci. 2021, 31, 1299-1327. [CrossRef]

45. An, R.; Zhang, C.; Sun, M.; Wang, H.; Shen, X.; Wang, B.; Xing, F.; Huang, X.; Fan, M. Monitoring grassland degradation and restoration using a novel climate use efficiency (NCUE) index in the Tibetan Plateau, China. Ecol. Indic. 2021, 131, 108208. [CrossRef]

46. Li, L.; Zhang, Y.; Liu, L.; Wang, Z.; Zhang, H.; Li, S.; Ding, M. Mapping Changing Population Distribution on the Qinghai-Tibet Plateau since 2000 with Multi-Temporal Remote Sensing and Point-of-Interest Data. Remote Sens. 2020, 12, 4059. [CrossRef]

47. Harris, R.B. Rangeland degradation on the Qinghai-Tibetan plateau: A review of the evidence of its magnitude and causes. J. Arid. Env. 2010, 74, 1-12. [CrossRef]

48. Gao, X.; Shi, X.; Lei, T. Influence of thawed soil depth on rainfall erosion of frozen bare meadow soil in the Qinghai-Tibet Plateau. Earth Surf. Proc. Land 2021, 46, 1953-1963. [CrossRef]

49. Cheng, G.; Wu, T. Responses of permafrost to climate change and their environmental significance, Qinghai-Tibet Plateau. J. Geophys. Res. Earth Surf. 2007, 112. [CrossRef]

50. Yao, T.; Thompson, L.; Yang, W.; Yu, W.; Gao, Y.; Guo, X.; Yang, X.; Duan, K.; Zhao, H.; Xu, B.; et al. Different glacier status with atmospheric circulations in Tibetan Plateau and surroundings. Nat. Clim. Chang. 2012, 2, 663-667. [CrossRef]

51. Yu, C.; Zhang, Y.; Claus, H.; Zeng, R.; Zhang, X.; Wang, J. Ecological and Environmental Issues Faced by a Developing Tibet. Environ. Sci. Technol. 2012, 46, 1979-1980. [CrossRef]

52. Liu, X.; Chen, B. Climatic warming in the Tibetan Plateau during recent decades. Int. J. Climatol. A J. R. Meteorol. Soc. 2000, 20, 1729-1742. [CrossRef]

53. Wang, Y.; Cheng, C.; Xie, Y.; Liu, B.; Yin, S.; Liu, Y.; Hao, Y. Increasing trends in rainfall-runoff erosivity in the Source Region of the Three Rivers, 1961-2012. Sci. Total Environ. 2017, 592, 639-648. [CrossRef]

54. Liu, B.; Tao, H.; Song, C.; Guo, B.; Shi, Z. Temporal and Spatial Variations of Rainfall Erosivity in Southwest China from 1960 to 2009. Adv. Earth Sci. 2012, 27, 499-509.

55. Hren, M.T.; Chamberlain, C.P.; Hilley, G.E.; Blisniuk, P.M.; Bookhagen, B. Major ion chemistry of the Yarlung TsangpoBrahmaputra river: Chemical weathering, erosion, and $\mathrm{CO}_{2}$ consumption in the southern Tibetan plateau and eastern syntaxis of the Himalaya. Geochim. Cosmochim. Acta 2007, 71, 2907-2935. [CrossRef]

56. He, Q.; Chen, S.; Dai, X. Assessing the effects of vegetation and precipitation on soil erosion in the Three-River Headwaters Region of the Qinghai-Tibet Plateau, China. J. Arid. Land 2020, 12, 865-886. [CrossRef]

57. Mengmei, W.; Suhua, F.U.; Baoyuan, L. Quantitative Research of Water Erosion on the Qinghai-Tibet Plateau. Adv. Earth Sci. 2021, 36, 740-752.

58. Piao, S.; Cui, M.; Chen, A.; Wang, X.; Ciais, P.; Liu, J.; Tang, Y. Altitude and temperature dependence of change in the spring vegetation green-up date from 1982 to 2006 in the Qinghai-Xizang Plateau. Agr. For. Meteorol. 2011, 151, 1599-1608. [CrossRef]

59. Zhu, D.; Xiong, K.; Xiao, H. Multi-time scale variability of rainfall erosivity and erosivity density in the karst region of southern China, 1960-2017. Catena 2021, 197, 104977. [CrossRef]

60. Gu, Z.; Feng, D.; Duan, X.; Gong, K.; Li, Y.; Yue, T. Spatial and temporal patterns of rainfall erosivity in the Tibetan Plateau. Water 2020, 12, 200. [CrossRef]

61. Fan, J.; Chen, Y.; Yan, D.; Guo, F. Characteristics of rainfall erosivity based on tropical rainfall measuring mission data in Tibet, China. J. Mt. Sci. 2013, 10, 1008-1017. [CrossRef]

62. Zhang, Y.; Li, B.; Zheng, D. Datasets of the boundary and area of the Tibetan Plateau. Acta Geogr. Sin. 2014, 69, 164-168.

63. Hu, Y.; Xu, J.; Huang, Y.; Zhou, Y.; Pang, Y.; Shi, Z.; Chen, X. Spatial and Temporal Variations in the Rainy Season Onset over the Qinghai-Tibet Plateau. Water 2019, 11, 1960. [CrossRef] 
64. Zheng, J.; Yin, Y.; Li, B. A new scheme for climate regionalization in China. Acta Geogr. Sin. 2010, 65, 3-12.

65. Gao, J.; Yao, T.; Masson-Delmotte, V.E.R.; Steen-Larsen, H.C.; Wang, W. Collapsing Glaciers Threaten Asia's Water Supplies. Nature 2019, 565, 19-21. [CrossRef]

66. Zheng, D. The system of physico-geographical regions of the Qinghai-Xizang (Tibet) Plateau. Sci. China Ser. D-Earth Sci. 1996, 39, 410-417.

67. Li, X.; Jiang, F.; Li, L.; Wang, G. Spatial and temporal variability of precipitation concentration index, concentration degree and concentration period in Xinjiang, China. Int. J. Clim. 2011, 31, 1679-1693. [CrossRef]

68. Kaplan, A.; Cane, M.A.; Kushnir, Y.; Clement, A.C.; Blumenthal, M.B.; Rajagopalan, B. Analyses of global sea surface temperature 1856-1991. J. Geophys. Res. Ocean. 1998, 103, 18567-18589. [CrossRef]

69. Trenberth, K.E. The definition of el nino. Bull. Am. Meteorol Soc. 1997, 78, 2771-2778. [CrossRef]

70. Wolter, K.; Timlin, M.S. El Niño/Southern Oscillation behaviour since 1871 as diagnosed in an extended multivariate ENSO index (MEI. ext). Int. J. Clim. 2011, 31, 1074-1087. [CrossRef]

71. Wolter, K.; Timlin, M.S. Monitoring ENSO in COADS with a Seasonally Adjusted Principal component index. In Proceedings of the 17th Climate Diagnostics Workshop, Noman, OK, USA, 18-23 October 1992; Volume 52, pp. 52-57.

72. Huang, B.; Thorne, P.W.; Banzon, V.F.; Boyer, T.; Chepurin, G.; Lawrimore, J.H.; Menne, M.J.; Smith, T.M.; Vose, R.S.; Zhang, H. Extended reconstructed sea surface temperature, version 5 (ERSSTv5): Upgrades, validations, and intercomparisons. J. Clim. 2017, 30, 8179-8205. [CrossRef]

73. Richardson, C.W.; Foster, G.R.; Wright, D.A. Estimation of Erosion Index from Daily Rainfall Amount. Trans. Am. Soc. Agric. Eng. 1983, 26, 153-160. [CrossRef]

74. Qin, W.; Guo, Q.; Zuo, C.; Shan, Z.; Ma, L.; Sun, G. Spatial distribution and temporal trends of rainfall erosivity in mainland China for 1951-2010. Catena 2016, 147, 177-186. [CrossRef]

75. Zhang, W.B.; Fu, J.S. Rainfall erosivity estimation under different rainfall amount. Resour. Sci. 2003, 25, 35-41.

76. Liu, S.; Huang, S.; Xie, Y.; Leng, G.; Huang, Q.; Wang, L.; Xue, Q. Spatial-temporal changes of rainfall erosivity in the loess plateau, China: Changing patterns, causes and implications. Catena 2018, 166, 279-289. [CrossRef]

77. Xin, Z.; Yu, X.; Li, Q.; Lu, X.X. Spatiotemporal variation in rainfall erosivity on the Chinese Loess Plateau during the period 1956-2008. Reg. Env. Chang. 2011, 11, 149-159. [CrossRef]

78. Sen, P.K. Estimates of the regression coefficient based on Kendall's tau. J. Am. Stat. Assoc. 1968, 63, 1379-1389. [CrossRef]

79. Kendall, M.G. Rank Correlation Methods; Griffin: London, UK, 1975.

80. Mann, H.B. Nonparametric tests against trend. Econom. J. Econom. Soc. 1945, 13, 245-259. [CrossRef]

81. Mitchell, J.M.; Dzerdzeevskii, B.; Flohn, H.; Hofmeyr, W.L.; Lamb, H.H.; Rao, K.N.; Wallen, C.C. Climate Change, WMO Technical Note No.79; World Meteorological Orgazination: Geneva, Switzerland, 1966; p. 79.

82. Beguería, S.; Serrano-Notivoli, R.; Tomas-Burguera, M. Computation of rainfall erosivity from daily precipitation amounts. Sci. Total Environ. 2018, 637, 359-373. [CrossRef]

83. Ray, D.K.; Ramankutty, N.; Mueller, N.D.; West, P.C.; Foley, J.A. Recent patterns of crop yield growth and stagnation. Nat. Commun. 2012, 3, 1293. [CrossRef]

84. Zhang, Z.; Lu, C. Identification of Maize Yield Trend Patterns in the North China Plain. Int. J. Plant. Prod. 2021, 15, 125-137. [CrossRef]

85. Schauberger, B.; Ben-Ari, T.; Makowski, D.; Kato, T.; Kato, H.; Ciais, P. Yield trends, variability and stagnation analysis of major crops in France over more than a century. Sci. Rep. 2018, 8, 16865. [CrossRef]

86. Zhang, Q.; Xu, C.; Jiang, T.; Wu, Y. Possible influence of ENSO on annual maximum streamflow of the Yangtze River, China. J. Hydrol. 2007, 333, 265-274. [CrossRef]

87. Jevrejeva, S.; Moore, J.C.; Grinsted, A. Influence of the Arctic Oscillation and El Niño-Southern Oscillation (ENSO) on ice conditions in the Baltic Sea: The wavelet approach. J. Geophys. Res. Atmos. 2003, 108. [CrossRef]

88. Torrence, C.; Compo, G.P. A practical guide to wavelet analysis. Bull. Am. Meteorol. Soc. 1998, 79, 61-78. [CrossRef]

89. Grinsted, A.; Moore, J.C.; Jevrejeva, S. Application of the cross wavelet transform and wavelet coherence to geophysical time series. Nonlinear Proc. Geoph. 2004, 11, 561-566. [CrossRef]

90. Schiemann, R.; Lüthi, D.; Schär, C. Seasonality and interannual variability of the westerly jet in the Tibetan Plateau region. J. Clim. 2009, 22, 2940-2957. [CrossRef]

91. Panagos, P.; Borrelli, P.; Meusburger, K.; Yu, B.; Klik, A.; Lim, K.J.; Yang, J.E.; Ni, J.; Miao, C.; Chattopadhyay, N.; et al. Global rainfall erosivity assessment based on high-temporal resolution rainfall records. Sci. Rep. 2017, 7, 4175. [CrossRef]

92. Shin, J.; Kim, T.; Heo, J.; Lee, J. Spatial and temporal variations in rainfall erosivity and erosivity density in South Korea. Catena 2019, 176, 125-144. [CrossRef]

93. Li, L.; Yang, S.; Wang, Z.; Zhu, X.; Tang, H. Evidence of warming and wetting climate over the Qinghai-Tibet Plateau. Arct. Antarct. Alp. Res. 2010, 42, 449-457. [CrossRef]

94. Sato, T.; Kimura, F. How does the Tibetan Plateau affect the transition of Indian monsoon rainfall? Mon. Weather Rev. 2007, 135, 2006-2015. [CrossRef]

95. Zhou, T.; Gao, J.; Zhao, Y.; Zhang, L.; Zhang, W. Water Vapor Transport Processes on Asian Water Tower. Bull. Chin. Acad. Sci. 2019, 34, 1210-1219.

96. Stocking, M.A.; Elwell, H.A. Rainfall erosivity over Rhodesia. Trans. Inst. Br. Geogr. 1976, 1, 231-245. [CrossRef] 
97. Paliaga, G.; Donadio, C.; Bernardi, M.; Faccini, F. High-resolution lightning detection and possible relationship with rainfall events over the Central Mediterranean Area. Remote Sens. 2019, 11, 1601. [CrossRef]

98. Nearing, M.A.; Yin, S.; Borrelli, P.; Polyakov, V.O. Rainfall erosivity: An historical review. Catena 2017, 157, 357-362. [CrossRef]

99. Lai, C.; Chen, X.; Wang, Z.; Wu, X.; Zhao, S.; Wu, X.; Bai, W. Spatio-temporal variation in rainfall erosivity during 1960-2012 in the Pearl River Basin, China. Catena 2016, 137, 382-391. [CrossRef]

100. Huang, J.; Zhang, J.; Zhang, Z.; Xu, C. Spatial and temporal variations in rainfall erosivity during 1960-2005 in the Yangtze River basin. Stoch. Environ. Res. Risk Assess. 2013, 27, 337-351. [CrossRef]

101. Panagos, P.; Ballabio, C.; Borrelli, P.; Meusburger, K.; Klik, A.; Rousseva, S.; Tadić, M.P.; Michaelides, S.; Hrabalíková, M.; Olsen, P.; et al. Rainfall erosivity in Europe. Sci. Total Environ. 2015, 511, 801-814. [CrossRef] [PubMed]

102. Chen, H. Projected change in extreme rainfall events in China by the end of the 21st century using CMIP5 models. Chin. Sci. Bull. 2013, 58, 1462-1472. [CrossRef]

103. Immerzeel, W.W.; Van Beek, L.P.; Bierkens, M.F. Climate change will affect the Asian water towers. Science 2010, 328, 1382-1385. [CrossRef]

104. Zhang, J.; Li, D.; Wang, W. Influence of terrain on precipitation in Qinghai-Tibet Plateau during summer monsoon. Sci. Geogr. Sin. 2008, 28, 235.

105. Wang, Z.; Zhang, Y.; Yang, Y.; Zhou, W.; Gang, C.; Zhang, Y.; Li, J.; An, R.; Wang, K.; Odeh, I.; et al. Quantitative assess the driving forces on the grassland degradation in the Qinghai-Tibet Plateau, in China. Ecol. Inf. 2016, 33, 32-44. [CrossRef]

106. Chen, T.; Jiao, J.; Wang, H.; Zhao, C.; Lin, H. Progress in Research on Soil Erosion in Qinghai-Tibet Plateau. Acta Pedol. Sin. 2019, 57, 547-564.

107. Zhang, Y.; Liu, L.; Wang, Z.; Bai, W.; Ding, M.; Wang, X.; Yan, J.; Xu, E.; Wu, X.; Zhang, B.; et al. Spatial and temporal characteristics of land use and cover changes in the Tibetan Plateau. Chin. Sci. Bull. 2019, 64, 2865-2875.

108. Cao, Q.; Hao, Z.; Yuan, F.; Su, Z.; Berndtsson, R.; Hao, J.; Nyima, T. Impact of ENSO regimes on developing-and decaying-phase precipitation during rainy season in China. Hydrol. Earth Syst. Sci. 2017, 21, 5415-5426. [CrossRef]

109. Cai, Z.; Tian, L.; Bowen, G.J. ENSO variability reflected in precipitation oxygen isotopes across the Asian Summer Monsoon region. Earth Planet. Sci. Lett. 2017, 475, 25-33. [CrossRef]

110. Kumar, K.K.; Rajagopalan, B.; Hoerling, M.; Bates, G.; Cane, M. Unraveling the mystery of Indian monsoon failure during El Niño. Science 2006, 314, 115-119. [CrossRef] [PubMed] 